\title{
BCL-xL/BCL2L1 is a critical anti-apoptotic protein that promotes the survival of differentiating pancreatic cells from human pluripotent stem cells
}

Larry Sai Weng Loo ${ }^{1,2}$, Andreas Alvin Purnomo Soetedjo ${ }^{1}$, Hwee Hui Lau ${ }^{1,2}$, Natasha Hui Jin Ng${ }^{1}$, Soumita Ghosh ${ }^{3}$, Linh Nguyen ${ }^{1,4}$, Vidhya Gomathi Krishnan ${ }^{5}$, Hyungwon Choi ${ }^{3}$, Xavier Roca ${ }^{2}$, Shawn Hoon ${ }^{5}$ and Adrian Kee Keong Teo (iD) $1,4,6$

\begin{abstract}
The differentiation of human pluripotent stem cells into pancreatic cells involves cellular proliferation and apoptosis during cell fate transitions. However, their implications for establishing cellular identity are unclear. Here, we profiled the expression of $\mathrm{BCL}-2$ family of proteins during pancreatic specification and observed an upregulation of $\mathrm{BCL}-\mathrm{xL}$, downregulation of BAK and corresponding downregulation of cleaved CASP3 representative of apoptosis.

Experimental inhibition of $\mathrm{BCL}-\mathrm{xL}$ reciprocally increased apoptosis and resulted in a decreased gene expression of pancreatic markers despite a compensatory increase in anti-apoptotic protein BCL-2. RNA-Seq analyses then revealed a downregulation of multiple metabolic genes upon inhibition of BCL-XL. Follow-up bioenergetics assays revealed broad downregulation of both glycolysis and oxidative phosphorylation when $B C L-x L$ was inhibited. Early perturbation of $\mathrm{BCL}-\mathrm{xL}$ during pancreatic specification also had subsequent detrimental effects on the formation of $\mathrm{INS}^{+}$pancreatic beta-like cells. In conclusion, the more differentiated pancreatic progenitors are dependent on anti-apoptotic BCL-XL for survival, whereas the less differentiated pancreatic progenitors that survived after WEHI-539 treatment would exhibit a more immature phenotype. Therefore, modulation of the expression level of $B C L-x L$ can potentially increase the survival and robustness of pancreatic progenitors that ultimately define human pancreatic beta cell mass and function.
\end{abstract}

\section{Introduction}

Human pluripotent stem cells (hPSCs), an umbrella term for human embryonic stem cells (hESCs) and human-induced pluripotent stem cells (hiPSCs), are now routinely differentiated into desired human cell types for studying human organ development, in vitro disease modeling or even potential cell replacement therapy ${ }^{1}$. In the context of diabetes, hPSCs can now be differentiated

\footnotetext{
Correspondence: Adrian Kee Keong Teo (drainteo@gmail.com)

${ }^{1}$ Stem Cells and Diabetes Laboratory, Institute of Molecular and Cell Biology, A*STAR, Proteos, Singapore 138673, Singapore

${ }^{2}$ School of Biological Sciences, Nanyang Technological University, Singapore 637551, Singapore

Full list of author information is available at the end of the article

Edited by M. Herold
}

into pancreatic progenitors with ease and subsequently to achieve $20-40 \%$ insulin $^{+}$pancreatic beta-like cells ${ }^{2}$.

During the exit from pluripotency toward lineage specification, a significant amount of cell death is typically observed $^{3,4}$. While programmed cell death or apoptosis is well-known to be involved in developmental processes ${ }^{5}$, detailed mechanisms, especially in the context of hPSC differentiation, remain to be elucidated. In particular, a combination of cellular apoptosis, differentiation, and proliferation could be taking place concurrently as hPSCs are being directed into a particular lineage such as the pancreatic cells.

The BCL-2 family of proteins are notable for their involvement in the promotion or inhibition of apoptosis ${ }^{6}$. BAX and BAK are the two main multidomain pro-apoptotic 
members required for the execution phase of the mitochondrial apoptosis pathway ${ }^{7}$, whereas BCL2, BCL-xL (gene/transcript name BCL2L1), MCL1, BCL2A1, and $\mathrm{BCL}-\mathrm{W}$ are the common anti-apoptotic proteins that promote cell survival ${ }^{8}$. The balance between the antiapoptotic and pro-apoptotic members ultimately determines whether a cell lives or dies. For instance, BCL2 is known to promote the survival of $\mathrm{hESCs}^{9}$, whereas proapoptotic BAX is known to cull hESCs with genomic mutations and DNA damage rapidly ${ }^{10}$. Currently, the roles of these BCL-2 family of proteins in hPSC lineage differentiation are poorly understood.

Here, we differentiated hPSCs into pancreatic progenitors and uncovered a unique reciprocal relationship between anti-apoptotic BCL-xL and pro-apoptotic BAK proteins. $\mathrm{BCL}-\mathrm{xL}$ was found to be important in the early pancreatic progenitor stage in suppressing cleaved caspase-3 activation. When BCL-xL expression or function was inhibited experimentally, early human pancreatic differentiation from hPSCs was disrupted, leading to metabolic alterations and less efficient formation of insulin $^{+}$pancreatic beta-like cells. Together, we report a previously underappreciated role of $\mathrm{BCL}-\mathrm{xL}$ in promoting the survival of differentiating pancreatic progenitors from hPSCs. Well-differentiated pancreatic progenitors are highly dependent on BCL-xL for their pancreatic identity as determined by their pancreatic marker gene expression. Therefore, modulation of the expression level of BCL-xL during hPSC differentiation may be one potential means to improve the efficiency of differentiation and survival of human pancreatic progenitors.

\section{Results}

Anti-apoptotic BCL-xL and pro-apoptotic BAK proteins exhibit opposite trends during pancreatic specification from hPSCs

During our routine differentiation of hPSCs into pancreatic progenitors using our previously described 17-day (D) differentiation protocol (Fig. 1a, S1a-c) ${ }^{11,12}$, we typically observe increased cell death in the first 5 days marking the transition from pluripotency at D0-D5 primitive gut tube before a significant decrease in cell death starting from D7 early pancreatic progenitors (Fig. 1b). To understand the molecular changes underlying this phenomenon, we decided to evaluate the protein expression profile of several common members of the BCL-2 family (Fig. 1c, d). After washing away the dead cells, the protein expression of the live cells was assessed using western blot analysis. The BH3-only proteins BIM and PUMA did not reflect reproducible changes from D0 to D17 of pancreatic differentiation. Although pro-apoptotic proteins BAX and BAK are known to heterodimerize to execute apoptosis, we found BAX to be expressed at constant levels whereas BAK was surprisingly decreased from D7 onwards.
Conversely, multidomain anti-apoptotic protein $\mathrm{BCL}-\mathrm{xL}$ exhibited a reciprocal increase in protein expression from D7 onwards, whereas anti-apoptotic protein BCL2 or MCL1 were unchanged throughout differentiation (Fig. 1c, d). These observations were confirmed in both $\mathrm{H} 9$ hESCs (Fig. 1c) and another independent hiPSC line, iAGb (Fig. 1d). This reciprocal upregulation of BCL-xL and downregulation of BAK protein expression coincided with a decrease in cleaved CASP3 expression from D7 onwards (Fig. 1c, d), suggesting the unique importance of $\mathrm{BCL}-\mathrm{xL}$ but not BCL2 or MCL1 in promoting the survival of differentiating pancreatic progenitors from D7. Immunostaining analyses also confirmed an upregulation of BCL-xL protein from D3 to D12 (Fig. 1e). To confirm if there is a direct reciprocal relationship between $\mathrm{BCL}-\mathrm{xL}$ and $\mathrm{BAK}$, we overexpressed $\mathrm{BCL}-\mathrm{xL}$ in undifferentiated hPSCs and evaluated the expression of BAK. While BCL$\mathrm{xL}$ protein was successfully overexpressed, there was no appreciable effect on BAK protein expression (Fig. 1f), suggesting that this reciprocal relationship is indirect. Together, these data suggest that anti-apoptotic BCL-xL protein could be involved during early human pancreatic specification in culture.

\section{Experimental inhibition of $\mathrm{BCL}-\mathrm{xL}$ protein function increases apoptosis during pancreatic specification}

Since BCL-xL expression started to increase on D7 of our differentiation, we decided to assess the importance of $\mathrm{BCL}-\mathrm{xL}$ protein during early pancreatic specification at this timepoint (Fig. 2a). We used a specific and high affinity BCL-xL inhibitor, WEHI-539, that interacts with the binding groove of BCL-xL (but does not act on BCL2) to inhibit its anti-apoptotic activity ${ }^{13}$. An increasing dose of WEHI-539 from $10 \mathrm{nM}$ to $100 \mu \mathrm{M}$ on D7 cells resulted in a decrease in BCL-xL protein and, a reciprocal increase in BCL2 and cleaved CASP3 protein levels (Fig. 2b), suggesting that $\mathrm{BCL}-\mathrm{xL}$ is indeed involved in suppressing cleaved CASP3 in the pancreatic progenitors to prevent cell death. Importantly, pro-apoptotic BAK protein levels remained high despite an increase in $\mathrm{BCL} 2$ protein expression, indicating that $\mathrm{BCL}-\mathrm{xL}$ (but not $\mathrm{BCL} 2$ ) is the main anti-apoptotic protein that promotes cell survival during pancreatic specification. The increase in cleaved CASP3 expression upon inhibition of BCL-xL with WEHI-539 was confirmed via immunostaining analyses (Fig. 2c). We also assessed the percentage of live versus dead adherent cells across eight timepoints and our data showed that increased cell death was observed on D12 and D17 upon WEHI-539 treatment (Fig. 2d), suggesting that the later stage of differentiating pancreatic progenitors could be more reliant on BCL-xL for survival. QPCR analyses then demonstrated that 5-10 $\mu \mathrm{M}$ WEHI-539 treatment resulted in decreased $B C L 2 L 1$ transcript levels but not any of the other BCL-2 family members that we 


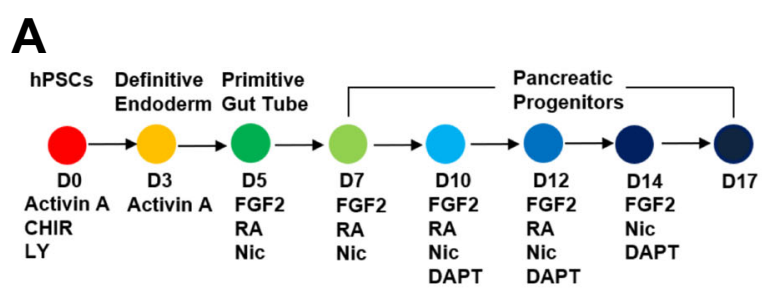

C

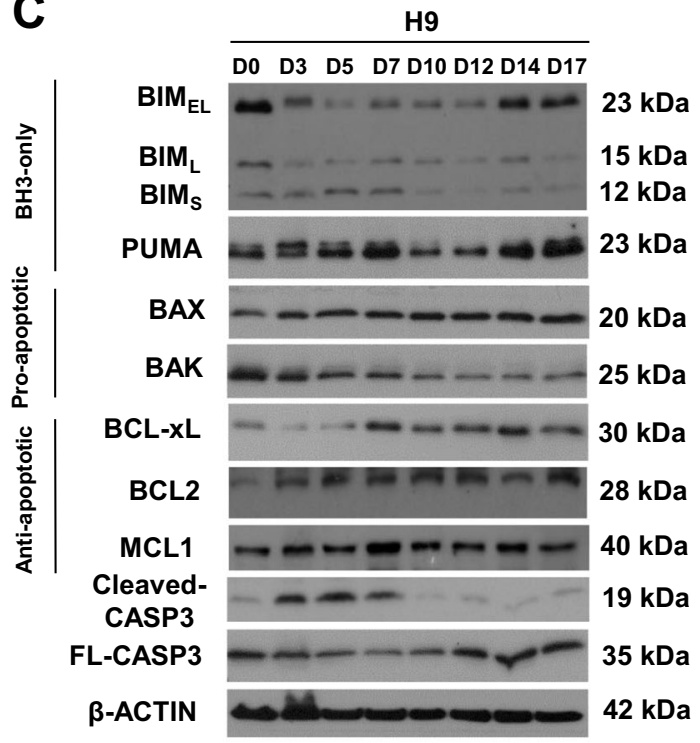

$\mathbf{E}$
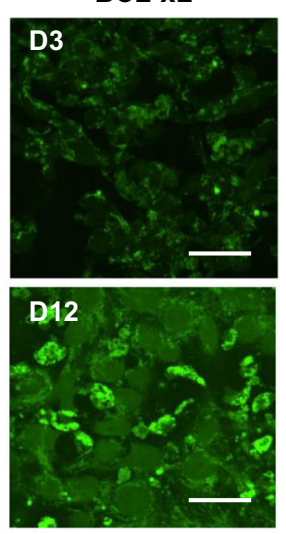

DAPI
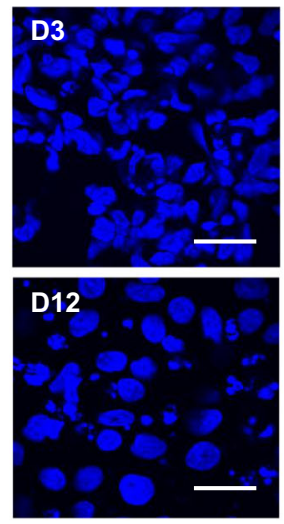

D
B

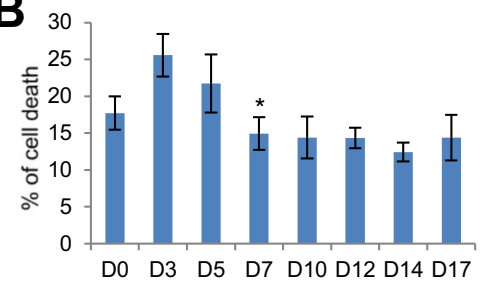

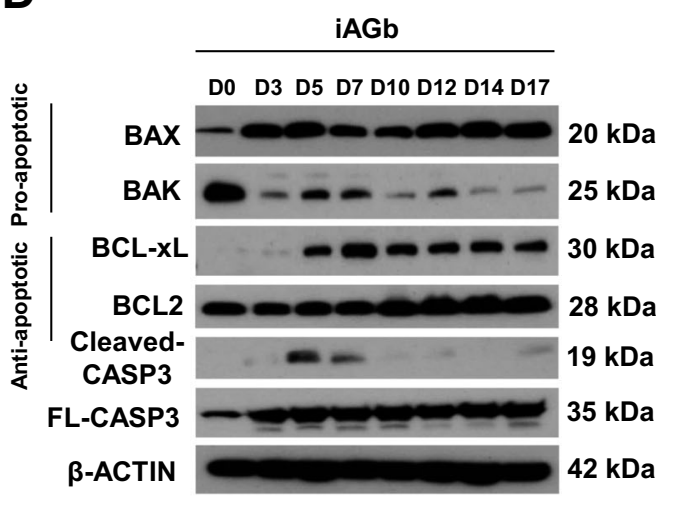

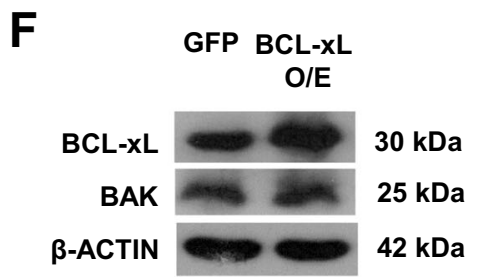

Fig. 1 Anti-apoptotic BCL-xL and pro-apoptotic BAK proteins exhibit opposite trends during pancreatic specification from human pluripotent stem cells. a Schematic showing 17D differentiation protocol used to generate early pancreatic progenitors. Respective growth factors used are depicted at each time point. b Trypan blue staining showing the \% of cell death over the course of 17D differentiation. Error bars indicate standard deviation of three biological replicates undergoing independent differentiations. Asterisk $\left(^{*}\right)$ indicates $P<0.05$ compared between D5 and D7. Western blot showing the expression of BCL-2 proteins over the course of 17D differentiation in $\mathbf{c} H 9 \mathrm{hESCs}$ and $\mathbf{d}$ iAGb hiPSCs. e Immunofluorescence staining for BCL-xL protein on D3 and D12 cells. Scale bar represents $50 \mu \mathrm{m}$. $\mathbf{f}$ Western blot showing the expression of BAK protein upon overexpression of BCL-xL in undifferentiated hPSCs. "See also Fig. S1".

evaluated (Fig. 2e). We then co-treated D7 cells with WEHI-539 and QVD-OPh, an irreversible pan-caspase inhibitor, to block WEHI-539-induced cell death. Upon addition of QVD-OPh, we observed a rescue of $B C L 2 L 1$ transcript expression in the WEHI-539-treated samples (Fig. 2f), suggesting that cells with high BCL2L1 expression were indeed selectively killed when $\mathrm{BCL}-\mathrm{xL}$ was inhibited by WEHI-539 treatment. 
A

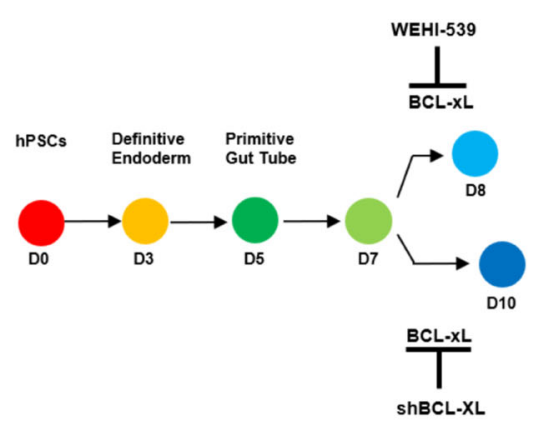

C Cleaved-
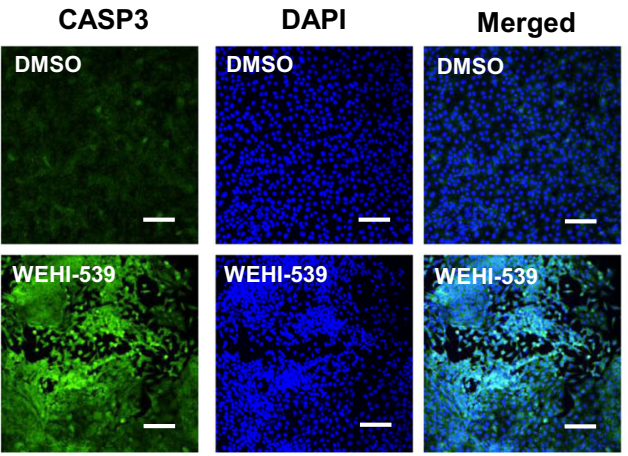

D

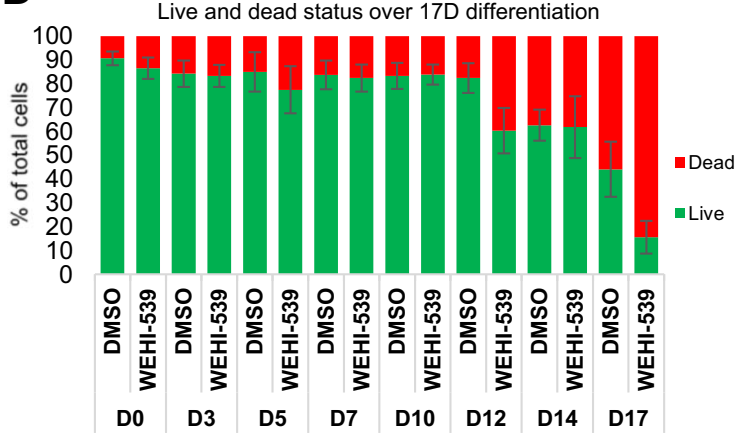

$\mathbf{F}$

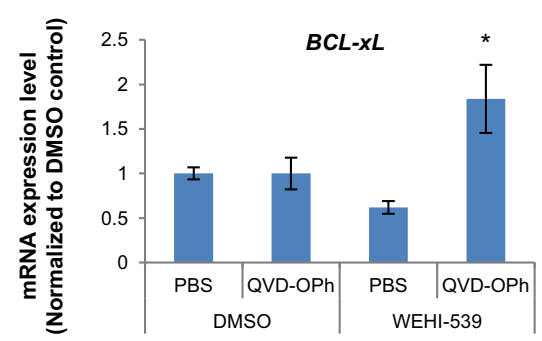

B

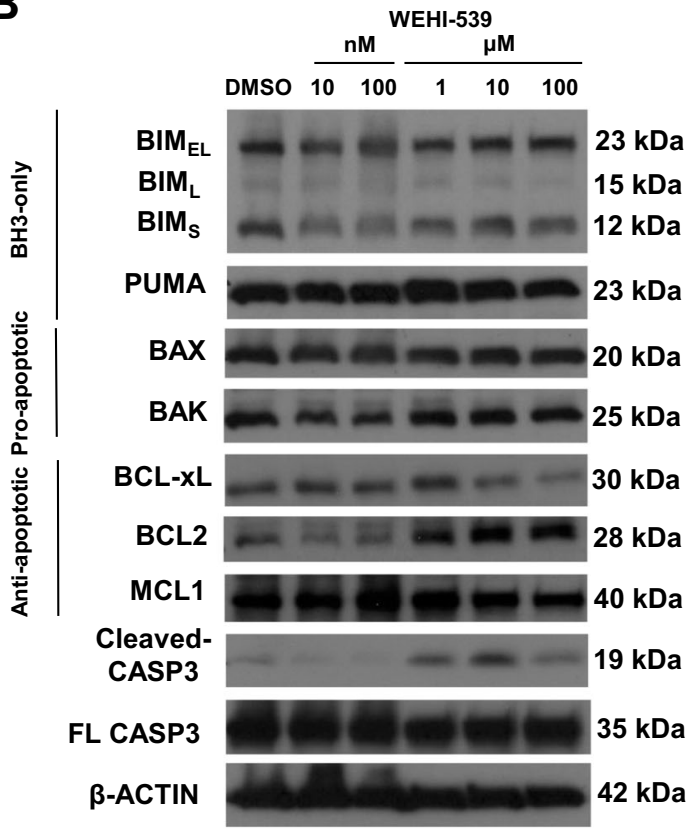

E Anti-apoptotic

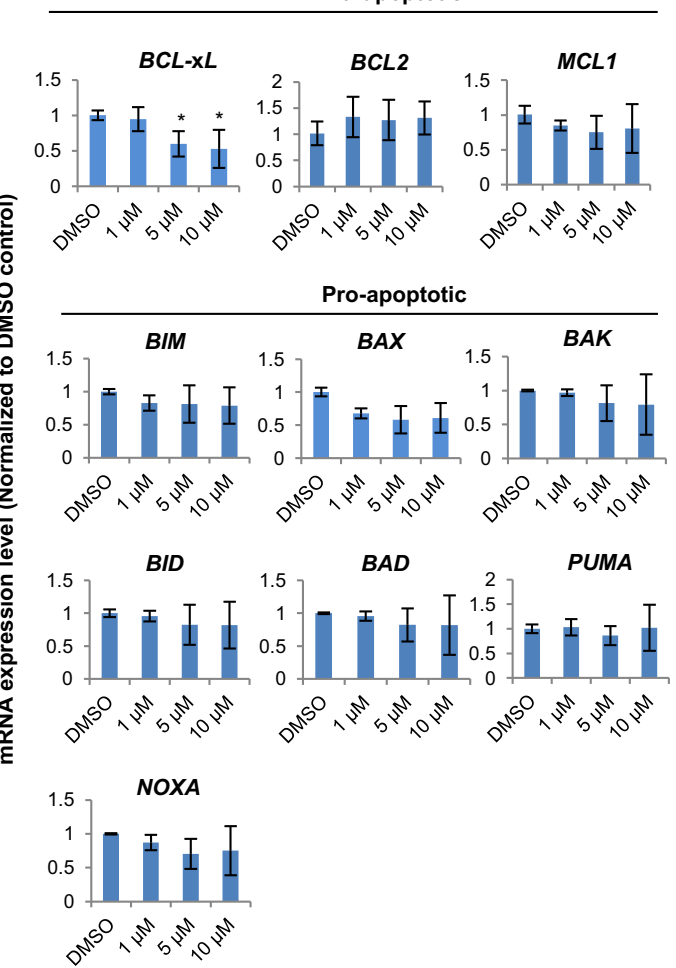

Fig. 2 Inhibition of BCL-xL protein function increases apoptosis from D7 onwards. a Schematic showing the usage of WEHI- 539 or shBCL2L1 to inhibit BCL-xL at D7 during pancreatic specification. $\mathbf{b}$ Western blot showing the expression of BCL-2 proteins upon treatment with WEHI-539 on D7 cells. c Immunofluorescence staining for cleaved CASP3 protein on cells treated with DMSO or WEHI-539. Scale bar represents $100 \mu \mathrm{m}$. d LIVE/DEAD Viability/Cytotoxicity to quantify the percentage of live and dead cells after treatment with DMSO or WEHI-539 on all eight timepoints during pancreatic differentiation. e Expression of anti-apoptotic and pro-apoptotic gene transcripts upon treatment with WEHI-539 on D7 cells. $\mathbf{f}$ Expression of $B C L-x L$ gene transcripts upon treatment with WEHI-539 and QVD-OPh on D7 cells. Error bars indicate standard deviation of three biological replicates undergoing independent differentiations. Asterisk $\left(^{*}\right)$ indicates $P<0.05$ compared to DMSO control by one-way ANOVA. A representative of at least two independent experiments is shown. "See also Fig. S2". 


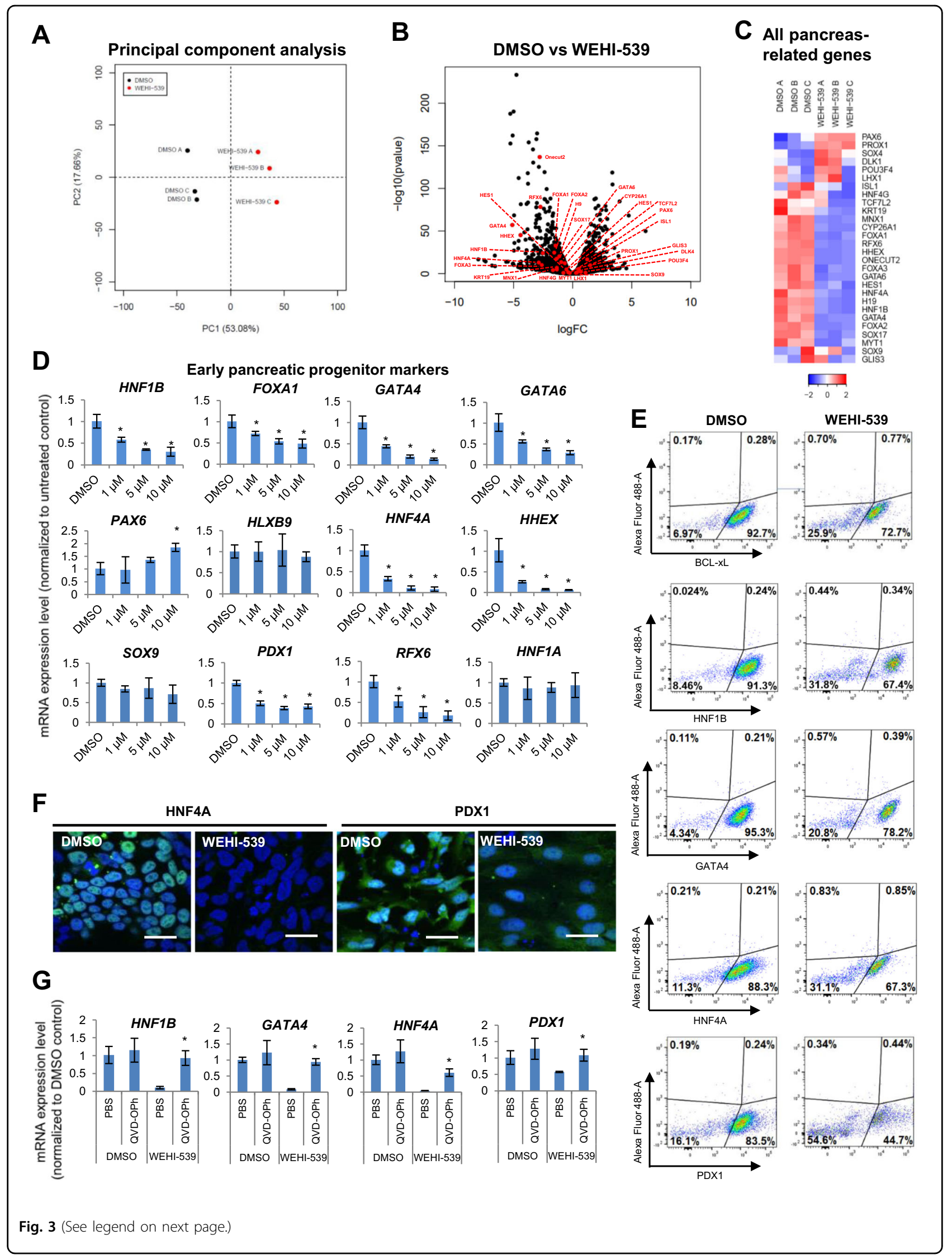


(see figure on previous page)

Fig. 3 RNA-Seq analyses reveal that the inhibition of BCL-xL function decreases the expression of pancreatic genes. a PCA or $\mathbf{b}$ geneexpression volcano plot of cells treated with DMSO or WEHI-539. c Hierarchical clustering heatmap analysis of pancreatic genes (red dots) in D7 cells treated with DMSO or WEHI-539. Colors in the heat map depict gene expression in units of SD from the mean across all samples (upregulation in red, downregulation in blue). $\mathbf{d}$ Expression of pancreatic gene transcripts upon treatment with WEHI-539 on D7 cells. e FACS analysis for BCL-xL, HNF1B, GATA4, HNF4A, and PDX1 proteins in cells treated with DMSO or WEHI-539. $\mathbf{f}$ Immunofluorescence staining for HNF4A and PDX1 proteins in cells treated with DMSO or WEHI-539. Scale bar represents $50 \mu \mathrm{m}$. g Expression of HNF1B, GATA4, HNF4A, and PDX1 gene transcripts upon treatment with WEHI-539 and QVD-OPh on D7 cells. Error bars indicate standard deviation of three biological replicates undergoing independent differentiations. Asterisk $\left(^{*}\right)$ indicates $P<0.05$ compared to DMSO control by one-way ANOVA. A representative of at least two independent experiments is shown. "See also Figs. S2 and S3".

RNA-Seq analyses reveal that the inhibition of $B C L-x L$ function kills the more differentiated pancreatic progenitors that are dependent on BCL-xL for survival,

leaving the less differentiated cells expressing lower level of pancreatic genes

To evaluate the global impact of BCL-xL inhibition on D7 cells, we performed genome-wide RNA-Seq analyses (Table S1). Principal component analyses indicated that triplicates of DMSO and WEHI-539-treated cells (dead cells had been washed away) clustered distinctly into two groups, suggesting that the inhibition of BCL-xL had an indirect impact on the overall transcriptome profile of these D7 cells (Fig. 3a). We then scrutinized many of the well-established early pancreatic markers and surprisingly found that they were mostly downregulated in the WEHI539 -treated cells as visualized from the volcano plot (Fig. 3b) and heatmap (Fig. 3c; FC $>1.5 ; P<0.05$ ). To confirm these observations, we performed QPCR analyses and validated a distinct dose-dependent downregulation of early pancreatic markers including that of $H N F 1 B$, FOXA1, GATA4, GATA6, HNF4A, HHEX, PDX1, and RFX6 when WEHI-539 was increased from 1 to $10 \mu \mathrm{M}$ (D7-D8 treatment; dead cells had been washed away) (Fig. 3d). However, the inhibition of BCL-xL function did not have a global impact on pancreatic gene expression as evidenced from the increase in $P A X 6$ gene expression and a lack of change in $H L X B 9, S O X 9$ or $H N F 1 A$ gene expression (Fig. 3d). We then confirmed the downregulation of several pancreatic genes at the protein level via FACS quantification (Fig. 3e; isotype control not shown) and immunostaining analyses (Fig. 3f). Next, we demonstrated that upon blocking apoptosis with a pancaspase inhibitor, QVD-OPh, there was increased survival of cells as compared to those treated with WEHI-539 only (Fig. S2a). We also observed a rescue of $B C L-x L / B C L 2 L 1$ (Fig. 2f), HNF1B, GATA4, HNF4A, and PDX1 transcript levels as compared to WEHI-539-treated cells (Fig. 3g). The results suggest that when apoptosis is blocked, the more differentiated pancreatic progenitors may have survived, leading to rescued levels of BCL2L1, HNF1B, GATA4, HNF4A, and PDX1 transcript expression.

To be certain of the importance of BCL-xL during the differentiation of pancreatic progenitors from hPSCs, we then cloned two independent shRNA constructs targeting $B C L 2 L 1$ transcript, generated lentiviruses, and transduced D7 cells to knockdown BCL2L1 before analyzing them on D10 (Fig. 2a). Upon successful knock down of BCL2L1 transcripts (Fig. S2b), we observed that the $\operatorname{sh} B C L 2 L 1$ pancreatic progenitors experienced higher cell death and appeared morphologically different (Fig. S2c). QPCR analyses further confirmed that many pancreatic genes such as HNF1B, FOXA1, GATA4, GATA6, HNF4A, $H H E X, P D X 1$, and RFX6 were similarly downregulated in $\operatorname{sh} B C L 2 L 1$ pancreatic progenitors as compared to control shSCR (scrambled; non-targeting) cells (Fig. S2d). We noted slight discrepancies in the gene expression of $P A X 6$, HLXB9, and HNF1A between one day of WEHI-539 treatment and 3 days of shRNA-mediated knockdown (Fig. S2d). We postulate that these differences could be attributed to differences between active inhibition of BCL$\mathrm{xL}$ protein function and an actual decrease in total $B C L 2 L 1$ transcript or BCL-xL protein availability. Nonetheless, pancreatic progenitor gene SOX9 remained unchanged in both treatment conditions. Together, our results highlight an important role for BCL-xL in establishing the survival and identity of well-differentiated pancreatic progenitors. Upon the loss of BCL-xL expression and function, the less differentiated pancreatic progenitors which are not so dependent on BCL-xL for survival, remain and express lower level of pancreatic genes.

\section{Wnt signaling that may play a role in pancreatic specification is perturbed in less differentiated pancreatic progenitors that are not reliant on $B C L-x L$ for survival}

Upon scrutinization of the RNA-Seq datasets, we also observed numerous genes in the Wnt signaling pathway that were differentially expressed when BCL-xL function was inhibited with WEHI-539 (Fig. 4a). Wnt signaling has been known to be involved in pancreas formation ${ }^{14}$ and is important for pancreatic growth ${ }^{15}$. Amongst the Wnt ligands, WNT2B, WNT5A, WNT5B, WNT7B, and $W N T 8 B$ gene expression was perturbed (Fig. 4b). Among the secreted Frizzled-related proteins (SFRPs), which are Wnt antagonists, SFRP5 was found to be downregulated in the less differentiated pancreatic progenitors (Fig. 4c). 
A
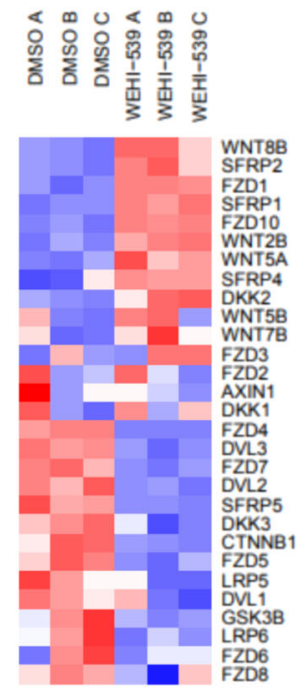

C

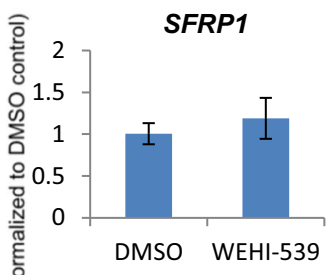

DMSO WEHI-539

SFRP4

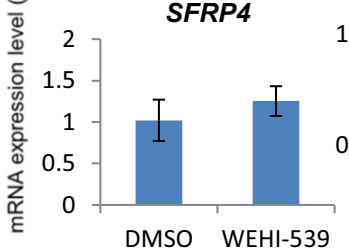

DMSO WEHI-539

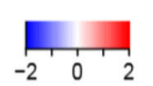

SFRP2

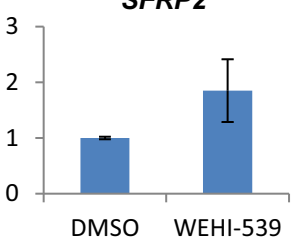

SFRP5

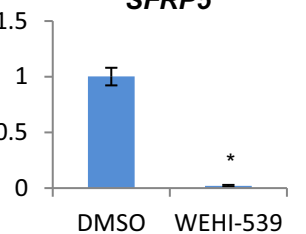

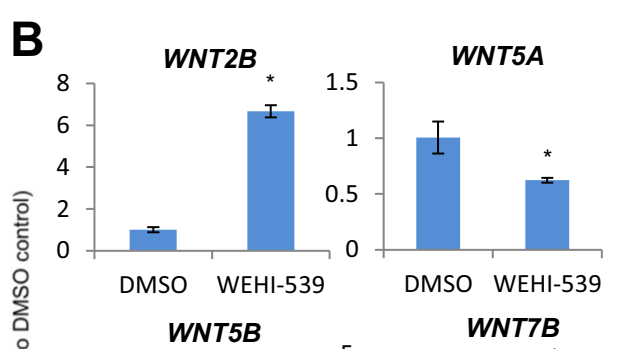
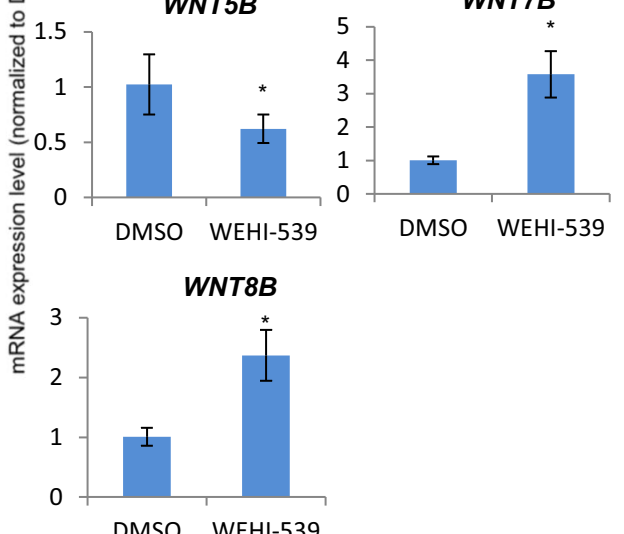

DMSO WEHI-539

\section{D}

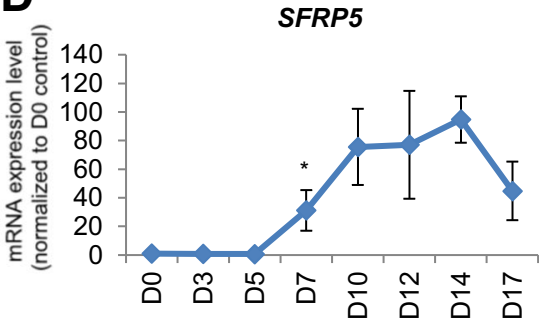

E

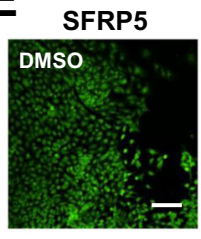

DAPI

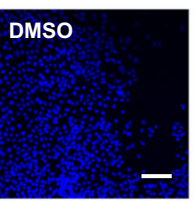

Merged

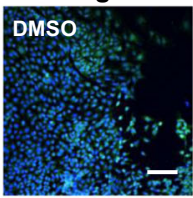

WEHI-539

WEHI-539

WEHI-539
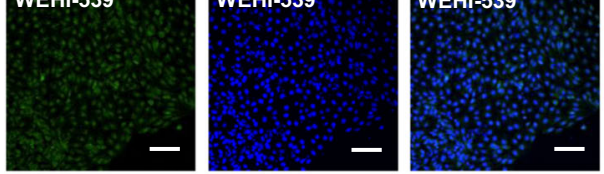

Fig. 4 Inhibition of BCL-xL function perturbs Wnt signaling that may play a role in pancreatic specification. a Hierarchical clustering heatmap analysis of Wnt signaling-associated genes in D7 cells treated with DMSO or WEHI-539. Colors in the heat map depict gene expression in units of SD from the mean across all samples (upregulation in red, downregulation in blue). Expression of $\mathbf{b}$ WNT or $\mathbf{c}$ SFRP family of transcripts upon treatment with WEHI-539 on D7 cells. d Expression of SFRP5 transcripts over the course of 17D differentiation in H9 hESCs. Error bars indicate standard deviation of three biological replicates undergoing independent differentiations. Asterisk $\left(^{*}\right)$ indicates $P<0.05$ compared to DMSO control or D0 by one-way ANOVA. A representative of at least two independent experiments is shown. e Immunofluorescence staining for SFRP5 protein on cells treated with DMSO or WEHI-539. Scale bar represents 100 m. "See also Fig. S3". 
Interestingly, SFRP5 transcripts were found to be increasingly expressed during pancreatic differentiation from hPSCs (Fig. 4d), suggesting its relevance in pancreatic progenitor formation. In addition, SFRP5 protein was found to be expressed in D7 pancreatic progenitors but its expression was diminished upon the inhibition of $\mathrm{BCL}-\mathrm{xL}$ protein function (Fig. 4e). In view that Sfrp5 has been suggested to be important for pancreatic bud formation in the Xenopus ${ }^{16}$ and also for gastrointestinal organogenesis in the zebrafish ${ }^{17}$, this decrease in SFRP5 expression could partly contribute to the broad downregulation of pancreatic marker gene expression upon loss of BCL-xL protein function.

Less differentiated pancreatic progenitors have decreased level of metabolic activity during pancreatic differentiation from hPSCs

Besides downregulation of pancreatic gene expression, our RNA-Seq and gene ontology analyses also revealed a downregulation of metabolic processes in the less differentiated pancreatic progenitors (Fig. S3a). This was further evidenced via heatmap analyses, demonstrating a distinct cluster of metabolic-related genes being broadly downregulated in less differentiated pancreatic progenitors (Fig. S3b, c). In view that metabolic processes broadly involve oxygen consumption and carbon dioxide production, we decided to evaluate glycolysis and oxidative phosphorylation processes in D7 pancreatic progenitors.

KEGG pathway mapping and heatmap analyses on multiple genes involved in glycolysis first reflected that most of them were downregulated in the less differentiated pancreatic progenitors (Fig. 5a, b). QPCR analyses further confirmed that glycolytic genes such as $H K 2$, $A L D O C$ and $E N O 2$ were downregulated in the less differentiated pancreatic progenitors (Fig. 5c). Pan-caspase inhibitor QVD-OPh was then added to block WEHI-539induced apoptosis and we observed a rescue of $H K 2$, $A L D O C$ and ENO2 transcript levels (Fig. S3d). When glycolysis stress test was performed on D7 pancreatic progenitors using the Seahorse bioenergetics assays, we detected lower extracellular acidification rate (from glycolysis-derived lactate) in both the less differentiated pancreatic progenitors from H9 hESCs (Fig. 5d) and iAGb hiPSCs (Fig. S4a). The rate of glycolysis (basal condition) and maximum glycolytic capacity (upon the injection of mitochondrial ATP synthase inhibitor, oligomycin) were consistently decreased in the less differentiated pancreatic progenitors (Figs. 5d, e, S4a, b). Interestingly, nonglycolytic acidification was also lower in the less differentiated pancreatic progenitors (Figs. 5e and S4b).

Next, we performed mito stress test to determine the mitochondrial function via oxygen consumption rate given that $\mathrm{BCL}-\mathrm{xL}$ is localized on the outer mitochondrial membrane. We detected lower basal respiration, ATP production, maximal respiration (facilitated by FCCP that disrupts mitochondrial membrane potential), and spare capacity (difference between maximal and basal respiration) in the less differentiated pancreatic progenitors after the more differentiated D7 pancreatic progenitors that were dependent on BCL-xL for survival were killed by WEHI-539 treatment (Figs. 5f, g and S4c, d). Together, these data indicated that the anti-apoptotic role of BCL$\mathrm{xL}$ in differentiating pancreatic progenitors contributes to their overall metabolic function and profile.

\section{Perturbation of $\mathrm{BCL}-\mathrm{xL}$ early on during pancreas specification has detrimental long-term impact on pancreatic beta cell formation}

Last but not least, to determine the relevance of $\mathrm{BCL}-\mathrm{xL}$ during early pancreatic progenitor formation on pancreatic beta-like cells, we further differentiated hPSCs into $\mathrm{INS}^{+}$pancreatic beta-like cells adapted from an established protocol (Fig. 6a) ${ }^{18}$. QPCR analyses confirmed that key pancreatic beta cell genes PDX1, MAFA, and INS increased in gene expression over the course of 35 days (Fig. 6b). While BCL2L1 gene expression was higher on D8 as compared to D0, interestingly, its expression continued to increase as INS transcripts were being expressed (Fig. 6b), suggesting its involvement throughout the course of beta cell differentiation.

Therefore, we treated D8 pancreatic progenitors with BCL-xL inhibitor WEHI-539 and followed the cells as differentiation progressed to D35 pancreatic beta-like cells (Fig. S5). QPCR analyses revealed that the inhibition of BCL-xL function on D8 killed the BCL-xL-dependent pancreatic progenitors and led to a population of less differentiated pancreatic progenitors, ultimately leading to a decrease in key pancreatic beta cell gene expression including that of PDX1, MAFA, and INS (Fig. 6c). Together, these data indicated that $\mathrm{BCL}-\mathrm{xL}$ played an important anti-apoptotic role during early human pancreatic differentiation which had a long-term impact on the eventual pancreatic beta cell formation (Fig. 7a, b).

\section{Discussion}

The cell-type and developmental stage-specific effects of BCL2 $2^{19-21}, \mathrm{BCL}-\mathrm{xL}^{22-24}$, and other BCL-2 proteins have often been shown, both in genetic mouse models and human cells. Although both BCL-xL and BCL2 have been reported to be important in the pancreas, during the state of pancreatitis ${ }^{25}$, here, we report a unique reciprocal relationship between $\mathrm{BCL}-\mathrm{xL}$ (but not $\mathrm{BCL} 2$ ) and BAK during early human pancreatic differentiation.

In undifferentiated hPSCs, BAK, which has been shown to be essential for apoptosis ${ }^{26,27}$, is initially expressed at high levels. However, as pancreatic specification occurs from D7 onwards, BAK protein expression decreases, in concert with an increase in the protein expression of 


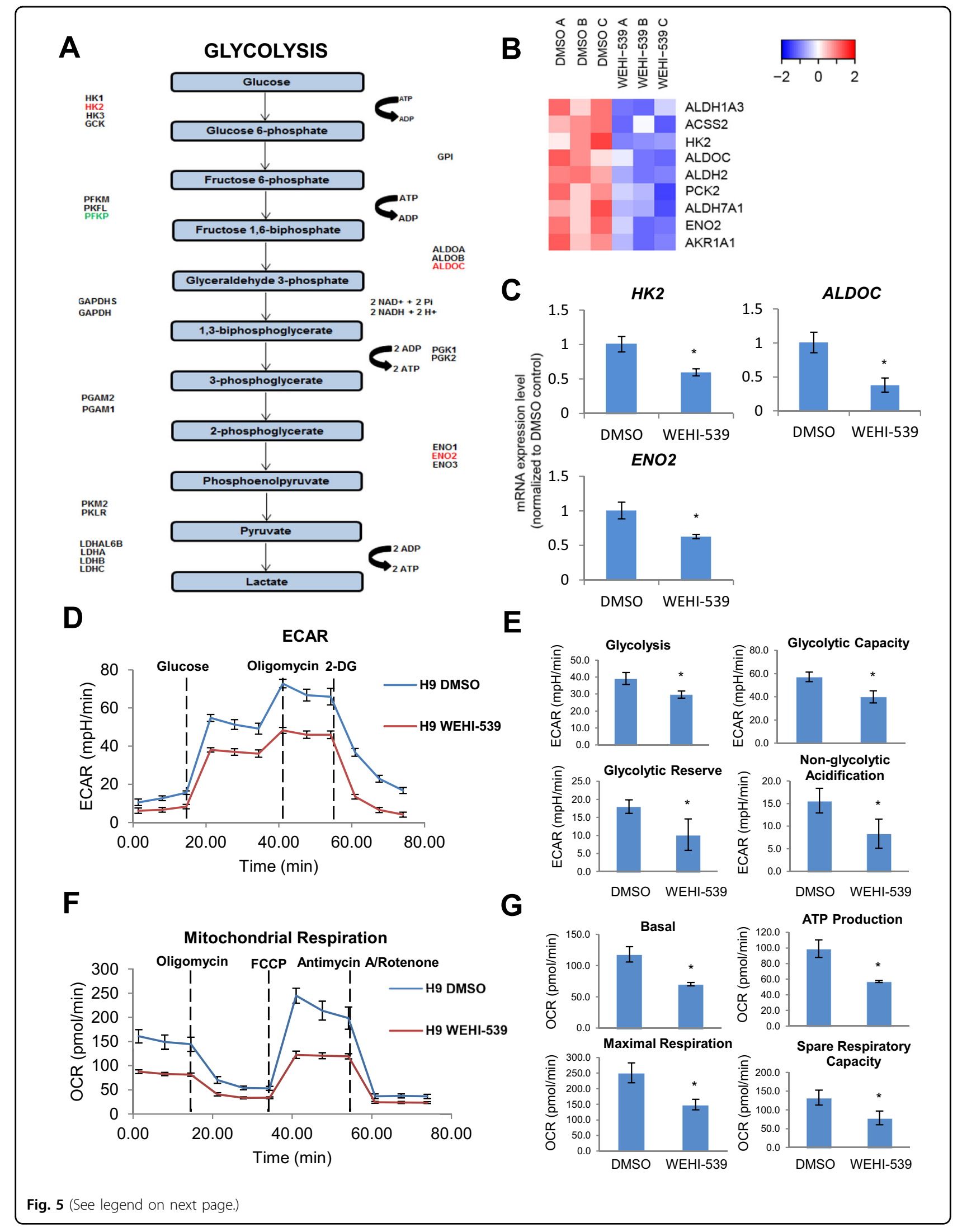


(see figure on previous page)

Fig. 5 BCL-xL function contributes to metabolic processes that occur during pancreatic specification. a Graphical representation of genes perturbed in the glycolysis pathway (upregulation in green and downregulation in red). b Hierarchical clustering heatmap analysis of metabolic genes in D7 cells treated with DMSO or WEHI-539. Colors in the heat map depict gene expression in units of SD from the mean across all samples (upregulation in red and downregulation in blue). c Expression of metabolic gene transcripts upon treatment with WEHI-539 on D7 cells. Error bars indicate standard deviation of three biological replicates undergoing independent differentiations. Asterisk (*) indicates $P<0.05$ compared to DMSO control. A representative of at least two independent experiments is shown. $\mathbf{d}$ Glycolysis stress test and $\mathbf{e}$ individual component graphs of glycolysis, glycolytic capacity, glycolytic reserve, and non-glycolytic acidification in D7 cells treated with DMSO or WEHI-539. $\mathbf{f}$ Mitochondrial respiration and $\mathbf{g}$ individual component graphs of basal mitochondrial respiration, ATP production, maximal respiration, and spare respiratory capacity in D7 cells treated with DMSO or WEHI-539. Error bars indicate standard deviation of eight replicates. Asterisk ${ }^{*}$ ) indicates $P<0.05$ compared to DMSO control. A representative of at least two independent experiments is shown. "See also Figs. S3 and S4".

BCL-xL and a decrease in downstream apoptotic cleaved caspase 3. The association of BCL-xL but not BCL2 with BAK has also been reported to keep apoptosis in check $^{28,29}$, albeit not specifically during pancreatic development. This is consistent with our findings that the compensatory increase in BCL2 protein expression upon BCL-xL inhibition with the highly specific WEHI-539 is insufficient to curb the BAK-mediated increase in cleaved caspase $3^{13}$ and the triggering of the caspase cascade. $B A K$ transcript levels did not change upon BCL-xL inhibition possibly because changes are only evident at the protein level. Additional experiments performed in undifferentiated hPSCs have confirmed that there is no direct inhibitory relationship between $\mathrm{BCL}-\mathrm{xL}$ and $\mathrm{BAK}$ expression levels as BAK protein level remained constant when BCL-xL was overexpressed in hPSCs. Apart from contributing to the survival of pancreatic progenitors, $\mathrm{BCL}-\mathrm{xL}$ has also been reported to be vital in ensuring the survival of neurons in the developing brain and spinal $\operatorname{cord}^{22}$.

Intriguingly, we found that the downregulation of BCL$\mathrm{xL}$ expression and function resulted in an indirect overall decrease in early pancreatic gene and protein expression due to survival of only the less differentiated pancreatic progenitors. While BCL-xL is known to be dispensable during rodent beta cell development, it is important for protection against apoptotic stimuli in mature beta cells ${ }^{23}$. The inhibition of BCL-xL with WEHI-539 could have resulted in higher death in cells that expressed high level of pancreatic markers. These more differentiated cells could be more sensitive to apoptosis and are dependent on anti-apoptotic BCL-xL for survival. This leaves behind less differentiated pancreatic progenitors that expressed lower levels of pancreatic genes. Therefore, we propose that BCL-xL plays an important permissive role in human pancreatic specification that is ultimately crucial for proper beta cell differentiation from hPSCs. While we found BCL-xL to play this role during human pancreatic specification possibly by supporting the survival of differentiating pancreatic progenitors, we do not rule out the importance of BCL2 or other anti-apoptotic proteins in this process. When WEHI-539-induced apoptosis was blocked by the addition of pan-caspase inhibitor QVD$\mathrm{OPh}$, we observed a rescue in the transcript levels of $B C L 2 L 1, H N F 1 B$, GATA4, HNF4A, and PDX1, indicating that the more differentiated pancreatic progenitors may have survived, leading to the observed rescue phenotype.

Upon inhibition of BCL-xL function in D7 pancreatic progenitors, we found perturbations in Wnt signaling molecules and a distinct downregulation of SFRP5 protein. Given the known role of Wnt signaling in pancreas development ${ }^{14,15}$ and the importance of Sfrp5 in pancreatic organogenesis in both the Xenopus ${ }^{16}$ and zebrafish $^{17}$, we postulate that this could partly contribute to the indirect effects of loss of $B C L 2 L 1 / \mathrm{BCL}-\mathrm{xL}$ gene and protein function on the overall downregulation of pancreatic marker gene expression in the remaining pancreatic progenitors. However, we do not rule out other possible mechanisms as well.

Interestingly, the inhibition of $\mathrm{BCL}-\mathrm{xL}$ function also indirectly affected metabolic processes in the residual pancreatic progenitors possibly due to the loss of cells that were more dependent on BCL-xL for survival. Since cellular metabolism can affect differentiation and development $^{30}$, we posit that this perturbation at the mitochondrial level also partly contributes to the mechanistic link between BCL-xL function and pancreatic development. BCL-xL has been reported to be directly involved in mitochondrial energetic capacity that is necessary for cell survival ${ }^{31}$. Inhibition of WEHI-539induced apoptosis demonstrated enhanced viability of pancreatic progenitors as evident by both the rescue of pancreatic and metabolic gene expression. Therefore, the loss of BCL-xL function could be more detrimental to pancreatic progenitors that are more differentiated and more dependent on BCL-xL for survival. In neurons, $\mathrm{BCL}-\mathrm{xL}$ deficiency results in a defect in the control of mitochondrial membrane potential, giving rise to a leaky inner mitochondrial membrane ${ }^{31}$. These BCL-xLdeficient cells eventually depolarize and die off as they are unable to maintain a normal membrane potential. Through interacting with the mitochondrial $F_{1} F_{0}$ ATP 


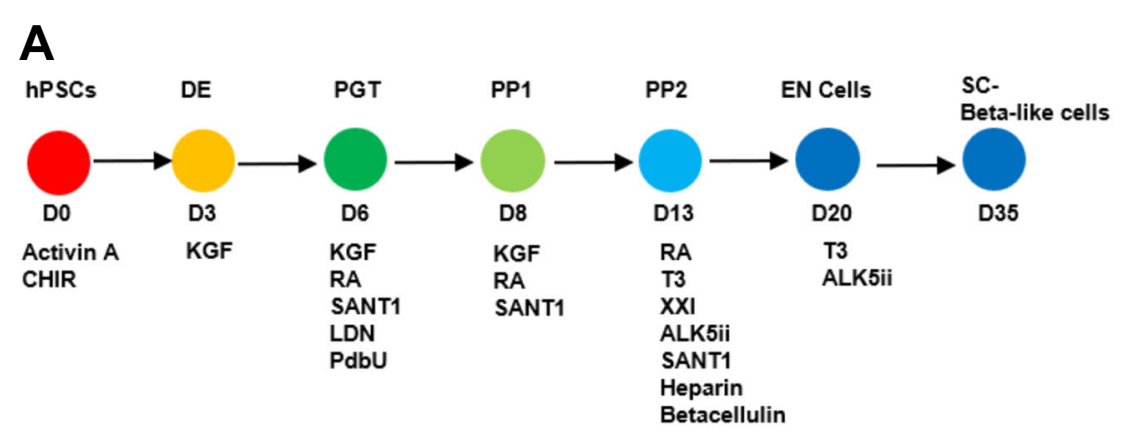

B

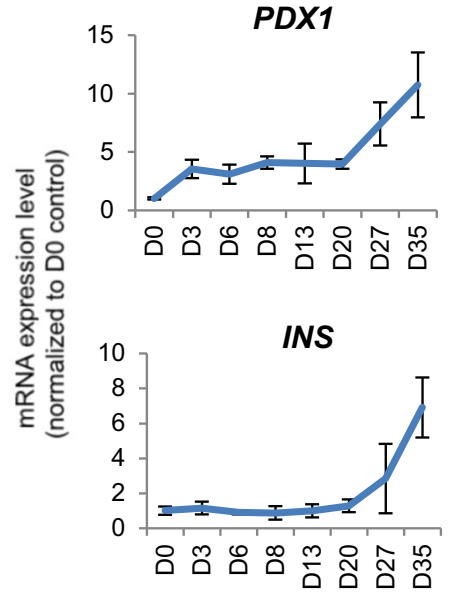

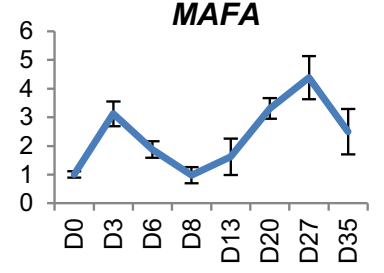

$B C L X L$

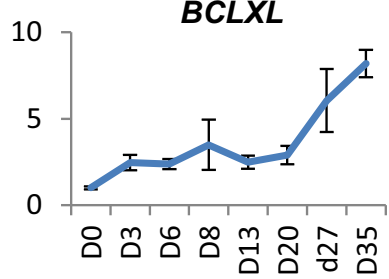

NKX6.1

C

PDX1

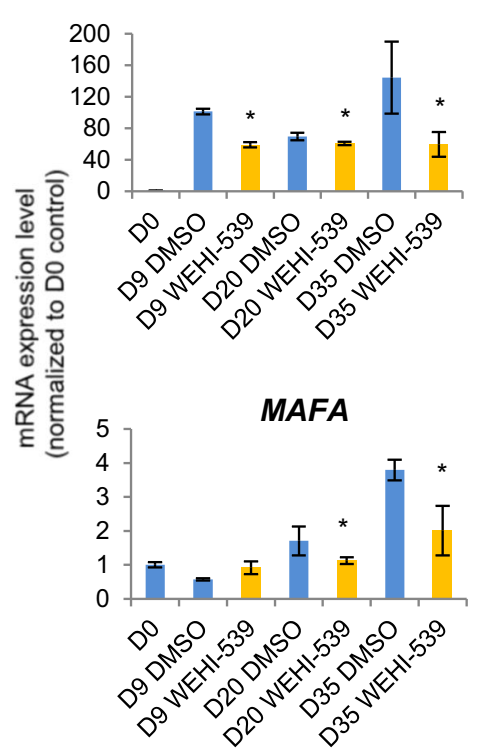

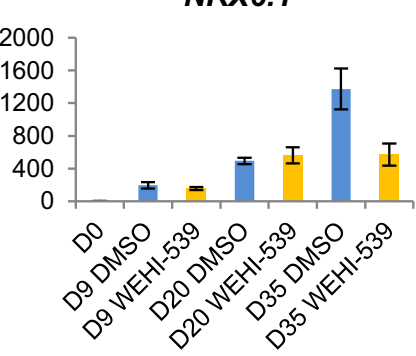

INS

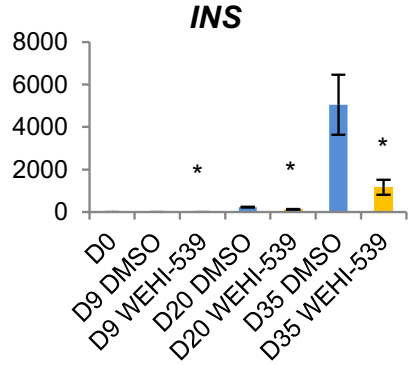

Fig. 6 Perturbation of BCL-xL early on during pancreas specification has detrimental long-term impact on pancreatic beta cell formation. a Schematic showing 35D differentiation protocol used to differentiate hPSCs into pancreatic beta-like cells. Respective growth factors used are depicted at each time point. b Expression of PDXI, MAFA, INS, and BCL-xL transcripts over the course of 35D differentiation in H9 hESCs. $\mathbf{c}$ Expression of PDX1, NKX6.1, MAFA, and INS transcripts upon treatment with WEHI-539 on D8 cells followed by the completion of 35D differentiation in H9 hESCs. Error bars indicate standard deviation of three biological replicates undergoing independent differentiations. Asterisk $\left(^{*}\right)$ indicates $P<0.05$ compared to DMSO control by one-way ANOVA. A representative of at least two independent experiments is shown. 


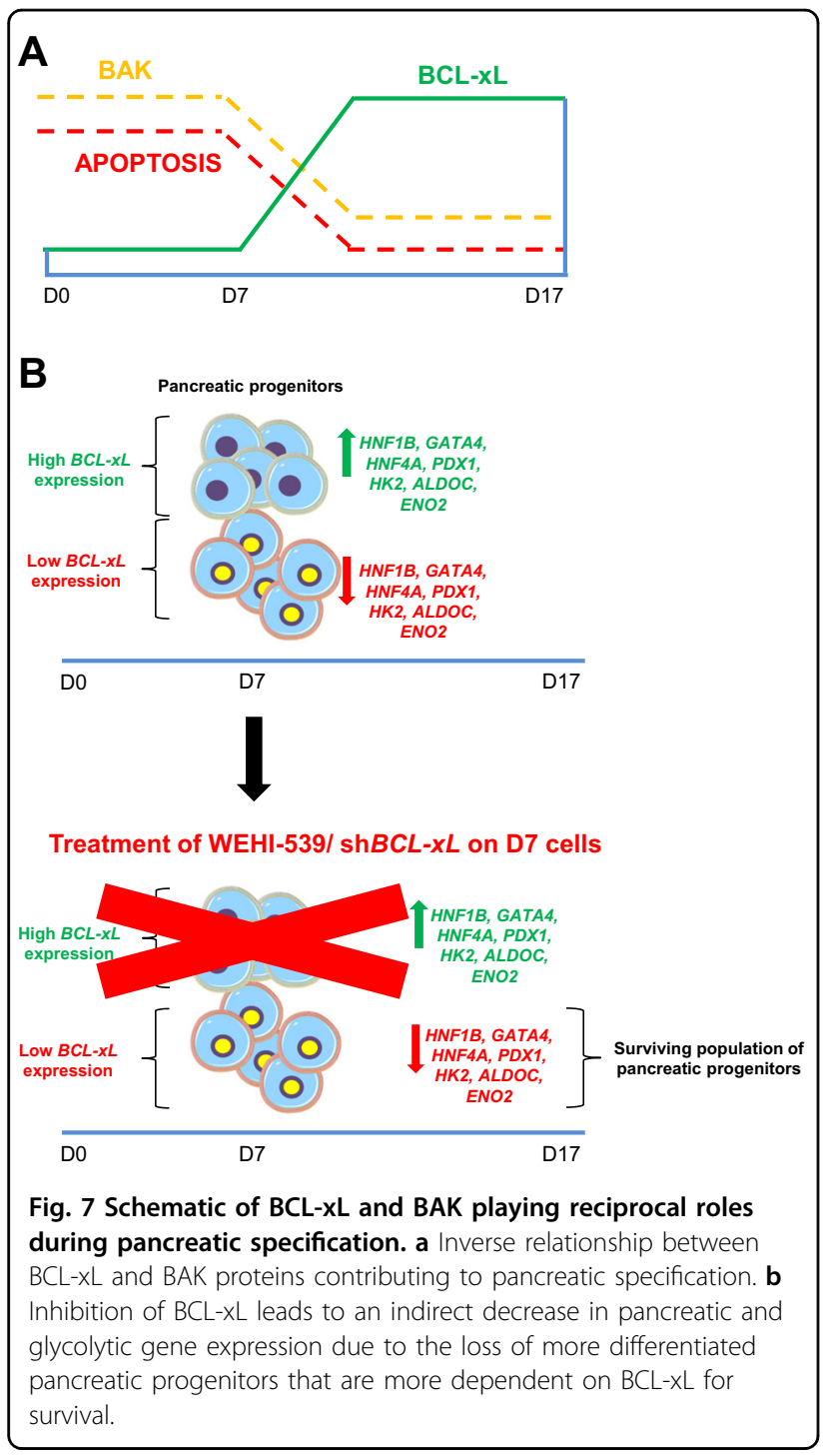

synthase, BCL-xL was also shown to regulate the metabolic efficiency of neurons ${ }^{24}$. These studies highlight the non-canonical role of BCL-xL in the regulation of metabolism in different cell types.

Together, we report a previously unappreciated role for BCL-xL in promoting the survival of differentiating pancreatic progenitors from hPSCs. Modulation of the expression level of $\mathrm{BCL}-\mathrm{xL}$ during human pancreatic specification from hPSCs could possibly be a means to improve the survival and robustness of pancreatic progenitors that ultimately determine pancreatic beta cell mass and function.

\section{Method}

hPSC culture, 17D differentiation, and 35D differentiation

Undifferentiated hPSCs were maintained in DMEM/F12 with $15 \mathrm{mM}$ HEPES (STEMCELL Technologies), 20\% KnockOut $^{\text {TM }}$ serum replacement (KOSR) (Gibco),
L-Glutamine (Sigma), NEAA (Life Technologies) and supplemented with $10 \mathrm{ng} / \mathrm{ml}$ FGF2 (Miltenyi Biotec) in $5 \% \mathrm{CO}_{2}$ and $100 \%$ humidity. hPSCs media were replaced every $24 \mathrm{~h}$. hPSCs were manually split and seeded on irradiated CF-1 mouse embryonic fibroblasts (MTI-GlobalStem) once a week.

$\mathrm{iAGb}$ was cultured in feeder-free condition using $\mathrm{TeSR}^{\mathrm{TM}}-\mathrm{E}^{\mathrm{TM}}$ basal medium and $\mathrm{TeSR}^{\mathrm{TM}}-\mathrm{E}^{\mathrm{TM}} 25 \times$ Supplement (STEMCELL Technologies). For 17D differentiation setup, the cells were processed as according to the 17D differentiation protocol described below.

293FT cells were cultured in DMEM High glucose (Life Technologies) supplemented with $10 \%$ Fetal bovine serum (South America Hyclone) and 1\% nonessential amino acid NEAA (Invitrogen).

All cell lines are screened routinely for mycoplasma contamination and are declared to be mycoplasma-free.

\section{D differentiation}

At D-2, confluent hPSCs in $10 \mathrm{~cm}$ dish were washed with sterile phosphate-buffered saline (PBS) and incubated with Dispase (STEMCELL Technologies) and Collagenase IV (Life Technologies) for $5 \mathrm{~min}$. The cells were then washed with sterile PBS, scored and passed through $70 \mu \mathrm{M}$ cell strainer. For each $10 \mathrm{~cm}$ plate, $6 \mathrm{ml} \mathrm{hPSC}$ medium was used to flush the plate and cell suspension collected. The cell suspension was then dispensed into a 6 well plate and left to incubate for $48 \mathrm{~h}$ at $5 \% \mathrm{CO}_{2}$ and $100 \%$ humidity.

Cells were differentiated 2 days later in RPMI-1640/2\% B-27 (no vitamin A; serum-free chemically defined medium (Gibco) supplemented with 1\% GlutaMAX Supplement (Invitrogen), 1\% MEM nonessential amino acids NEAA (Invitrogen), $0.1 \% \beta$-mercaptoethanol (Gibco). The component of each respective media is as follow: D0: $100 \mathrm{ng} / \mathrm{ml}$ Activin A (R\&D System). $3 \mu \mathrm{M}$ CHIR9021 (Tocris), $10 \mu \mathrm{M}$ LY294002 (LC Labs). D3: $50 \mathrm{ng} / \mathrm{ml}$ Activin A (R\&D Systems). D5: $50 \mathrm{ng} / \mathrm{ml} \mathrm{FGF2} \mathrm{(Miltenyi}$ Biotec) $+3 \mu$ M RA (Wako) $+10 \mathrm{mM} \mathrm{Nic} \mathrm{(Sigma).} \mathrm{D7:}$ $50 \mathrm{ng} / \mathrm{ml}$ FGF2 (Miltenyi Biotec) $+3 \mu \mathrm{M}$ RA (Wako) + $10 \mathrm{mM}$ Nic (Sigma). D10: $50 \mathrm{ng} / \mathrm{ml}$ FGF2 (Miltenyi Biotec) $+3 \mu$ M RA (WAKO) $+10 \mathrm{mM} \mathrm{Nic} \mathrm{(Sigma)}+20 \mu \mathrm{M}$ DAPT (Abcam). D12: $50 \mathrm{ng} / \mathrm{ml} \quad$ FGF2 $+3 \mu \mathrm{M} \quad$ RA $($ WAKO) $+10 \mathrm{mM}$ Nic (Sigma) $+20 \mu \mathrm{M}$ DAPT (Abcam). D14: $50 \mathrm{ng} / \mathrm{ml}$ FGF2 (Miltenyi Biotec) $+10 \mathrm{mM} \mathrm{Nic}$ (Sigma) $+20 \mu \mathrm{M}$ DAPT (Abcam). The cells were then harvested at each respective time-point for RNA and protein analysis.

\section{D differentiation}

At D-2, confluent hPSCs in $10 \mathrm{~cm}$ dish were washed with sterile PBS and incubated with $3 \mathrm{ml}$ of TrypLE (Life Technologies) for $3 \mathrm{~min}$. The cells were then washed with sterile PBS. $5 \mathrm{ml}$ of DMEM/F12 media were then 
dispensed into the dish to flush the cells and the cell solution was filtered through $70 \mu \mathrm{M}$ filter. The cells were centrifuged at $1200 \mathrm{rpm}$ for $5 \mathrm{~min}$ and seeded at 1 million $\mathrm{cell} / \mathrm{ml}$ in a low attachment plate. The plate was left to incubate for $48 \mathrm{~h}$ at $5 \% \mathrm{CO}_{2}$ and $100 \%$ humidity in a shaker at $80 \mathrm{rpm}$. The cells were differentiated using the growth factors on the respective days. D0: Activin A $100 \mathrm{ng} / \mathrm{ml}$ (R\&D system) + CHIR9021 (Tocris). D1: Activin A $100 \mathrm{ng} / \mathrm{ml}$ (R\&D system). D3: FGF7 $50 \mathrm{ng} / \mathrm{ml}$ (Mitenyi Biotec). D5: FGF7 $50 \mathrm{ng} / \mathrm{ml}$ (Mitenyi Biotec). D6: FGF7 $50 \mathrm{ng} / \mathrm{ml}$ (Mitenyi Biotec) + RA $2 \mu \mathrm{M}$ (WAKO) + Sant1 $0.25 \mu \mathrm{M}$ (Santa Cruz) + PDBu $500 \mathrm{nM}+$ LDN 200 nM. D7: FGF7 50 ng/ml (Mitenyi Biotec) + RA $2 \mu \mathrm{M}$ (WAKO) + Sant1 $0.25 \mu$ M (Santa Cruz) + PDBu 500 nM. D8: FGF7 $50 \mathrm{ng} / \mathrm{ml}$ (Mitenyi Biotec) + RA $100 \mathrm{nM}$ (WAKO) + Sant1 $0.25 \mu \mathrm{M}$ (Santa Cruz). D10: FGF7 $50 \mathrm{ng} / \mathrm{ml}$ (Mitenyi Biotec) + RA $10 \mathrm{nM}$ (WAKO) + Sant1 $0.25 \mu \mathrm{M}$ (Santa Cruz). D12: FGF7 $50 \mathrm{ng} / \mathrm{ml}$ (Mitenyi Biotec) + RA $100 \mathrm{nM}$ (WAKO) + Sant1 $0.25 \mu \mathrm{M}$ (Santa Cruz). D13: RA $100 \mathrm{nM}$ (WAKO) + Sant1 $0.25 \mu \mathrm{M}$ (Santa Cruz) + XXI $1 \mu \mathrm{M}$ (Millipore) + Alk5ill $10 \mu \mathrm{M}$ (ENZO) $+\mathrm{T} 31 \mu \mathrm{M}$ (Millipore) + Betacellulin $20 \mathrm{ng} / \mathrm{ml}$ (Cell Signaling). D15: RA $100 \mathrm{nM}$ (WAKO) + Sant1 $0.25 \mu \mathrm{M}$ (Santa Cruz) + XXI $1 \mu \mathrm{M}$ (Millipore) + Alk5ill $10 \mu \mathrm{M}$ (ENZO) $+\mathrm{T} 31 \mu \mathrm{M}$ (Millipore) + Betacellulin $20 \mathrm{ng} / \mathrm{ml}$ (Cell Signaling). D17: RA $25 \mathrm{nM}$ (WAKO) + XXI $1 \mu \mathrm{M}$ (Millipore) + Alk5ill $10 \mu \mathrm{M}+\mathrm{T} 31 \mu \mathrm{M}$ (Millipore) + Betacellulin $20 \mathrm{ng} / \mathrm{ml}$ (Cell Signaling). D19: RA $25 \mathrm{nM}$ (WAKO) + XXI $1 \mu \mathrm{M}$ (Millipore) + Alk5ill $10 \mu \mathrm{M}$ $($ ENZO) + T3 $1 \mu \mathrm{M}$ (Millipore) + Betacellulin $20 \mathrm{ng} / \mathrm{ml}$ (Cell Signaling). D20: Alk5ill $10 \mu \mathrm{M}$ (ENZO) $+\mathrm{T} 31 \mu \mathrm{M}$ (Millipore). D22: Alk5ill $10 \mu \mathrm{M}+\mathrm{T} 31 \mu \mathrm{M}$ (Millipore). D24: Alk5ill $10 \mu \mathrm{M}$ (ENZO) + T3 $1 \mu \mathrm{M}$ (Millipore). D26: Alk5ill $10 \mu \mathrm{M}+\mathrm{T} 31 \mu \mathrm{M}$ (Millipore). D28: Alk5ill $10 \mu \mathrm{M}$ (ENZO) $+\mathrm{T} 3 \quad 1 \mu \mathrm{M} \quad$ (Millipore). $\quad$ D30: Alk5ill $10 \mu \mathrm{M} \quad(\mathrm{ENZO})+\mathrm{T} 3 \quad 1 \mu \mathrm{M}$ (Millipore). D32: Alk5ill $10 \mu \mathrm{M} \quad$ (ENZO) $+\mathrm{T} 31 \mu \mathrm{M}$ (Millipore). D34: Alk5ill $10 \mu \mathrm{M}(\mathrm{ENZO})+\mathrm{T} 31 \mu \mathrm{M}$ (Millipore). The cells were then harvested at each respective time-point for RNA analysis.

\section{Cell culture treatment}

H9 cells were differentiated using 17D differentiation protocol to D7 and treated with $10 \mu \mathrm{M}$ of WEHI-539 (ApexBio), an inhibitor of BCL-xL. On D8, the cells were harvested for QPCR, western blot and immunostaining. $10 \mu \mathrm{M}$ broad-spectrum caspase inhibitor QVD-OPh (Cayman Chemical) was used to inhibit apoptosis.

\section{RNA extraction and RT-PCR}

RNA was extracted from the cells using RNA isolation Nucleospin ${ }^{\oplus}$ RNA (Macherey-Nagel). $350 \mu \mathrm{l}$ of RA1 buffer was added to each well of a 12-well plate. Cell homogenates were transferred to spin columns and processed as according to the manufacturer's instructions. Purified RNA was quantified using the NanoDrop 1000 spectrophotometer (Thermo Fisher Scientific). One microgram of RNA was converted to cDNA using High capacity cDNA Reverse Transcription Kit (Applied Biosystems). For 1 reaction, the following were mixed, $2 \mu \mathrm{l} 10 \times \mathrm{RT}$ buffer, $0.8 \mu \mathrm{l} 25 \times \mathrm{dNTP} \operatorname{mix}(100 \mathrm{mM}), 2 \mu \mathrm{l} 10 \times \mathrm{RT}$ random primers, $1 \mu \mathrm{l}$ Multiscribe ${ }^{\mathrm{TM}}$ reverse transcriptase. The mixture was topped up with respective amount of nuclease-free water to $20 \mu$ l. The protocol is as follows: $25^{\circ} \mathrm{C}$ for $10 \mathrm{~min}, 37^{\circ} \mathrm{C}$ for $120 \mathrm{~min}, 85^{\circ} \mathrm{C}$ for $5 \mathrm{~min}$, and $4{ }^{\circ} \mathrm{C}$ forever.

\section{Quantitative real-time PCR (QPCR)}

QPCR was performed on the CFX384 Touch $^{\text {Tw }}$ RealTime PCR Detection System with iTaq ${ }^{\text {Tht }}$ Universal SYBR Green Supermix (Bio-Rad). For 1 QPCR reaction, the following were mixed. Five microilitre SYBR Green Supermix, $300 \mathrm{nM}$ Forward primer, $300 \mathrm{nM}$ Reverse primer, $1.9 \mu \mathrm{l}$ nuclease-free water, $2.5 \mu \mathrm{l} \mathrm{cDNA}(2.5 \mathrm{ng} / \mu \mathrm{l})$ to a final volume of $10 \mu$ l. The samples were loaded in duplicate on a 384-well plate (Applied Biosystems). The thermal cycling condition was as follow: $95^{\circ} \mathrm{C}$ for $3 \mathrm{~min}$, $9^{\circ} \mathrm{C}$ for $5 \mathrm{~s}, 60^{\circ} \mathrm{C}$ for $30 \mathrm{~s}$, repeated for 39 cycles and then $65^{\circ} \mathrm{C}$ for $30 \mathrm{~s}, 65^{\circ} \mathrm{C}$ for $5 \mathrm{~s}$, and $4^{\circ} \mathrm{C}$ forever. Fold changes are normalized to $\beta$-actin gene expression and are based on relative expression values calculated using the $2^{-\Delta \Delta C(T)}$ method. QPCR primers were designed to span exon-exon junction, where possible, using Primer-BLAST (NCBI). Sequences of primers are listed in Table S2.

\section{SDS-PAGE/Western blot}

Cells were washed with PBS and treated with Trypsin for $5 \mathrm{~min}$ at $37^{\circ} \mathrm{C}$. Dislodged cells were neutralized with MEF media and centrifuged at $1500 \mathrm{rpm}$ for $5 \mathrm{~min}$ to obtain the cell pellet. Cell pellet were lysed in M-PER mammalian protein extraction reagent (Thermo Fisher Scientific) in the presence of protease and phosphatase inhibitors (Sigma). Protein lysates were then quantified using BCA assay kit (Thermo Fisher Scientific). Sodium dodecyl sulfate polyacrylamide gel electrophoresis (SDSPAGE) was performed using the Mini-PROTEAN Tetra Cell system (Bio-Rad) at $150 \mathrm{~V}$ for $1 \mathrm{~h}$. Forty microgram of proteins were then transferred to PVDF membranes (Bio$\mathrm{Rad})$ at $100 \mathrm{~V}$ for $1 \mathrm{~h}$. The blots were then blocked for $1 \mathrm{~h}$ in 5\% milk (Anlene nonfat milk) and probed with the respective primary antibodies and secondary antibodies, Primary antibodies used in this study: Mouse monoclonal anti- $\beta$-actin (1:10,000 Sigma, A5541), Rabbit polyclonal anti-BAX (1:1000, Cell Signaling Technologies, \#2772 S), Rabbit polyclonal anti-BAK (1:1000, Cell Signaling Technology, \#3814S), Rabbit polyclonal anti-BCL-xL (1:1000, Cell Signaling Technology \#2762S), Rabbit polyclonal anti-BCL2 (1:1000, Cell Signaling Technology 
\#2876), Rabbit polyclonal anti-BIM (1:1000, Cell Signaling Technology \#2819S), Rabbit polyclonal anti-Caspase 3 (1:1000, Cell Signaling Technology, \#9662S), Rabbit polyclonal anti-MCL1 (1:1000, Cell Signaling Technology, \#4572), Rabbit polyclonal anti-PUMA (1:1000, Cell Signaling Technology \#4976). Secondary used in this study: Goat anti-rabbit IgG HRP (1:10,000, Santa Cruz, sc-2004), Goat anti-mouse IgG HRP (1:10,000, Santa Cruz, sc2005). Chemiluminescent signals were detected using Super Signal ${ }^{\mathrm{TM}}$ West Dura Extended Duration substrate (Thermo Fisher Scientific).

\section{Immunostaining}

At the end of each differentiation time-point, cells on coverslips (Marienfeld) were washed with DPBS and fixed with $4 \%$ paraformaldehyde for $20 \mathrm{~min}$ at room temperature. Cells were blocked with DPBS containing 5\% donkey serum and $0.1 \%$ Triton $\mathrm{X}-100$ at $4{ }^{\circ} \mathrm{C}$ for $1 \mathrm{~h}$ before overnight incubation with primary antibodies at $4{ }^{\circ} \mathrm{C}$. Primary antibodies used in this study: Rabbit monoclonal anti-BCL-xL (1:1000, Abcam, Ab178844), Rabbit monoclonal anti-BCL2 (1:150, Abcam, Ab182858), Mouse monoclonal anti-BAK (1:1000, Abcam, Ab104124), Mouse monoclonal anti-GATA4 (1:1000, Thermo Fisher Scientific, MA5-15532), Goat polyclonal anti-HNF1 $\beta$ (1:100, Abcam, Ab59118), Rabbit monoclonal antiHNF4 $\alpha$ (1:1000, Cell Signaling Technology \#3113), Goat polyclonal anti-PDX1 (1:20, R\&D Systems, Af2419), Rabbit polyclonal anti-Caspase 3 (1:200, Abcam, Ab13847), cells were incubated in the dark with secondary antibodies diluted in DPBS containing $0.1 \%$ Triton X-100 for $1 \mathrm{~h}$ at $4{ }^{\circ} \mathrm{C}$ before staining with DAPI (Sigma) for $20 \mathrm{~min}$ at $4{ }^{\circ} \mathrm{C}$. Secondary antibodies used in this study: Alex Fluor Plus 647 Donkey Anti-Mouse IgG $(\mathrm{H}+\mathrm{L})$ (1:500, Invitrogen, Ab32787), Alexa Fluor 488 Donkey Anti-Rabbit IgG (H + L) (1:500, Invitrogen, A21206), Alex Fluor 488Donkey Anti-Goat IgG (H+L) (1:500, Thermo Fisher Scientific, A11055), Alex Fluor 488 Donkey AntiMouse $(\mathrm{H}+\mathrm{L})$ (1:500, Thermo Fisher Scientific, A21202). The coverslips were mounted onto SuperFrost Plus ${ }^{\mathrm{TM}}$ Adhesion slides (Thermo Fisher Scientific) using DAKO mounting medium (DAKO). Confocal images were acquired with the Olympus FV1000 inverted confocal microscope using the Olympus Fluoview v3.1 software. Brightfield images were acquired with the Axiovert $200 \mathrm{M}$ inverted microscope using the Axiovision LE software version 4.8.2.

\section{Live and dead cell assay}

hPSCs were differentiated to D17 and for each of the eight timepoints during pancreatic differentiation, the differentiating cells were treated with DMSO or WEHI539. Prior to staining, the cells were washed twice with
DPBS. The LIVE/DEAD ${ }^{\text {mM }}$ Viability/Cytotoxicity Kit (Thermo Fisher Scientific) was allowed to thaw to room temperature. $2 \mu \mathrm{l}$ thD-1: $0.5 \mu \mathrm{l}$ CalceinAM were added to $1 \mathrm{ml}$ of DPBS. For each well of 12-well plate, $90 \mu \mathrm{l}$ of the staining solution was used and left to incubate for $10 \mathrm{~min}$ at room temperature. The staining solution was removed and washed with DPBS. Confocal images were acquired with the Olympus FV1000 inverted confocal microscope using the Olympus Fluoview v3.1 software. Brightfield images were acquired with the Axiovert $200 \mathrm{M}$ inverted microscope using the Axiovision LE software version 4.8.2. Stained cells were then counted from an average of at least ten images using ImageJ software.

\section{Fluorescence-activated cell sorting (FACS)}

Differentiated cells were harvested by mechanical scraping using a cell scraper and dissociated into single cells following incubation with $0.25 \%$ Trypsin/EDTA at $37^{\circ} \mathrm{C}$. Single cells were collected by passing the suspension through a $40 \mu \mathrm{m}$ cell strainer. Cells were pelleted by centrifugation at $1200 \mathrm{rpm}$ for 5 minutes. Supernatant was aspirated and cells were washed with DPBS, followed by fixation with $4 \%$ paraformaldehyde on ice for $1 \mathrm{~h}$. Fixed cells were washed with DPBS before blocking in FACS buffer (5\% FBS in DPBS) containing $0.1 \%$ Triton X-100 on ice for $1 \mathrm{~h}$. Cells were incubated with primary antibodies for $1 \mathrm{~h}$ at $4^{\circ} \mathrm{C}$ and washed with FACS buffer containing $0.1 \%$ Triton X-100 prior to addition of secondary antibodies. Cells were incubated with secondary antibodies in the dark for $1 \mathrm{~h}$ at $4{ }^{\circ} \mathrm{C}$. After washing, cells were resuspended in FACS buffer before analysis using the $\mathrm{BD}^{\mathrm{TM}}$ LSR II Flow Cytometer. Data analysis were performed using the FlowJo 7.0 software.

\section{Lentiviral-mediated knockdown}

shRNAs targeting BCL2L1 (Sigma Construct: shRNA TRCN0000033500 and TRCN0000033501) were cloned into pLKO.1 vector. Plasmids were extracted using NucleoBond ${ }^{\oplus}$ Xtra Midi (Macherey-Nagel). The plasmids were packaged into virus using HEK293FT cells. Media was changed $24 \mathrm{~h}$ after transfection and left to incubate. Media was collected at 48 and $72 \mathrm{~h}$ and pooled. The lentivirus in the collected media was concentrated using ultra-clear tubes (Beckman Coulter) and placed in SW28 Ti swinging-bucket aluminum rotor (Beckman Coulter). The SW28 swinging-bucket rotor was loaded in Optima L-100 XP ultracentrifuge (Beckman Coulter) at centrifuged at $23,000 \mathrm{rpm}$ for $1.5 \mathrm{~h}$ at $4{ }^{\circ} \mathrm{C} .500 \mu \mathrm{l}$ of DMEM media was used to resuspend the pellet and the suspension was frozen at $-80^{\circ} \mathrm{C}$. hPSCs were differentiated to D6, trypsinized into single cells and replated at 400,000 cells per well in a 12-well plate. On D7, the single cells were transduced with the lentivirus with an MOI of 200 in 
$5 \mu \mathrm{g} / \mathrm{ml}$ polybrene (Millipore) for $24 \mathrm{~h}$. The medium was then changed to normal differentiation media and left to grow for an additional $48 \mathrm{~h}$.

\section{RNA sequencing and differential expression analysis}

Poly-A mRNA was enriched from $1 \mu \mathrm{g}$ of total RNA with oligo-dT beads (Invitrogen). Up to $100 \mathrm{ng}$ of poly-A mRNA recovered was used to construct multiplexed strand-specific RNA-seq libraries as per manufacturer's instruction (NEXTflex ${ }^{\text {TM }}$ Rapid Directional RNA-SEQ Kit, dUTP-Based, v2). Individual library quality was assessed with an Agilent 2100 Bioanalyzer and quantified with a QuBit 2.0 fluorometer before pooling for sequencing on a HiSeq $2000(1 \times 101 \mathrm{bp}$ read $)$. The pooled libraries were quantified using the KAPA quantification kit (KAPA Biosystems) prior to cluster formation. Adapter sequences and low quality bases in Fastq read sequences were trimmed using Trimmomatic (v.0.33) (parameters: LEADING:3 TRAILING:3 SLIDINGWINDOW:4:15 MINLEN:36). The quality filtered Fastq sequence reads were then aligned to the human genome (hg19) using Tophat (v.2.0.14) (parameters: --nocoverage-search --library-type $=$ fr-firststrand) and annotated with Ensembl gene IDs. The resulting bam files were used to generate feature read counts using the Python package-based htseq-count of HTSeq (v.0.6.1p1) (parameters: default union-counting mode, --strande$\mathrm{d}=$ reverse). The read count matrix output from HTSeq was used to perform differential expression analysis using the edgeR package (available in R (v.3.1.3)) in both 'classic' and generalized linear model $(\mathrm{glm})$ modes to contrast patient versus control. Procedures described in edgeR documentation were followed to calculate $P$ values, falsediscovery rate (FDR) adjusted $P$ values ( $q$-values) and fold-changes. A FDR cutoff of 0.05 was used to filter significantly differentially expressed genes. These genes with Ensembl IDs were mapped to gene symbols.

\section{Seahorse metabolic flux assay}

hESCs were differentiated to D7 using the 17D differentiation protocol and treated with DMSO or WEHI-539 (Apexbio) for $24 \mathrm{~h}$. D8 cells were then trypsinized and 150,000 cells plated per well on Seahorse XF96 cell culture microplates (Agilent). Growth media was changed to Seahorse XF Base Medium (Agilent) supplemented with L-Glutamine (Sigma) and placed in a non- $\mathrm{CO}_{2}$ incubator $1 \mathrm{~h}$ prior to assay. Glycolysis was measured via the Seahorse XF Glycolysis Stress Test Kit (Agilent) with a Seahorse XF 96 analyzer (Agilent) following the manufacturer's protocol. Using the same setup, oxidative phosphorylation was measured using Seahorse XF Mito Stress Kit (Agilent).

\section{Quantification and statistical analysis}

Statistical parameters for each experiment, including values of replicates and statistical significance, can be found in the figure legends. For dosage and time-point studies, one-way ANOVA was used to analyze differences in gene expression levels. All other statistical analyses were performed using Student's $t$ test (two-sided; equal variance). $P$ values of less than 0.05 were considered significant.

\section{Key resources table}

\begin{tabular}{|c|c|c|}
\hline Reagent or resource & Source & Identifier \\
\hline \multicolumn{3}{|l|}{ Antibodies } \\
\hline $\begin{array}{l}\text { Anti- } \beta \text {-actin (Mouse } \\
\text { monoclonal) }\end{array}$ & Sigma & $\begin{array}{l}\text { A5441; RRID: } \\
\text { AB_476744 }\end{array}$ \\
\hline $\begin{array}{l}\text { Anti-BAX [2D2] Mouse } \\
\text { monoclonal }\end{array}$ & Abcam & $\begin{array}{l}\text { Ab77566; } \\
\text { RRID: } \\
\text { AB_1565901 }\end{array}$ \\
\hline Anti-BAX (Rabbit polyclonal) & $\begin{array}{l}\text { Cell Signaling } \\
\text { Technology }\end{array}$ & $\begin{array}{l}\text { \#2772S; RRID: } \\
\text { AB_10695870 }\end{array}$ \\
\hline $\begin{array}{l}\text { Anti BAK [AT8B4] (Mouse } \\
\text { monoclonal) }\end{array}$ & Abcam & $\begin{array}{l}\text { Ab104124; } \\
\text { RRID: } \\
\text { AB_10712355 }\end{array}$ \\
\hline Anti-BAK (Rabbit polyclonal) & $\begin{array}{l}\text { Cell Signaling } \\
\text { Technology }\end{array}$ & $\begin{array}{l}\text { \#3814S; RRID: } \\
\text { AB_2290287 }\end{array}$ \\
\hline $\begin{array}{l}\text { Anti -BCL-xL [EPR16642] } \\
\text { (Rabbit monoclonal) }\end{array}$ & Abcam & $\begin{array}{l}\text { Ab178844; } \\
\text { RRID: NA }\end{array}$ \\
\hline $\begin{array}{l}\text { Anti-BCL-xL (Rabbit } \\
\text { polyclonal) }\end{array}$ & $\begin{array}{l}\text { Cell Signaling } \\
\text { Technology }\end{array}$ & $\begin{array}{l}\# 2762 S ; \text { RRID: } \\
\text { AB_10694844 }\end{array}$ \\
\hline $\begin{array}{l}\text { Anti-BCL2 [EPR17509] (Rabbit } \\
\text { monoclonal) }\end{array}$ & Abcam & $\begin{array}{l}\text { Ab182858; } \\
\text { RRID: } \\
\text { AB_2715467 }\end{array}$ \\
\hline Anti-BCL2 (Rabbit polyclonal) & $\begin{array}{l}\text { Cell Signaling } \\
\text { Technology }\end{array}$ & $\begin{array}{l}\text { \#2876; RRID: } \\
\text { AB_2064177 }\end{array}$ \\
\hline Anti-BIM (Rabbit polyclonal) & $\begin{array}{l}\text { Cell Signaling } \\
\text { Technology }\end{array}$ & $\begin{array}{l}\text { \#2819S; RRID: } \\
\text { AB_10692515 }\end{array}$ \\
\hline $\begin{array}{l}\text { Anti-Caspase } 3 \text { (Rabbit } \\
\text { monoclonal) }\end{array}$ & Abcam & $\begin{array}{l}\text { Ab13847; } \\
\text { RRID: } \\
\text { AB_443014 }\end{array}$ \\
\hline $\begin{array}{l}\text { Anti-Caspase } 3 \text { (Rabbit } \\
\text { polyclonal) }\end{array}$ & $\begin{array}{l}\text { Cell Signaling } \\
\text { Technology }\end{array}$ & $\begin{array}{l}\text { \#9662S; RRID: } \\
\text { AB_10694681 }\end{array}$ \\
\hline $\begin{array}{l}\text { Anti-GATA4 [6H10] (Mouse } \\
\text { monoclonal) }\end{array}$ & Thermo Fisher Scientific & $\begin{array}{l}\text { MA5-15532; } \\
\text { RRID: } \\
\text { AB_10989032 }\end{array}$ \\
\hline Anti-HNF1 $\beta$ (Goat polyclonal) & Abcam & $\begin{array}{l}\text { Ab59118; } \\
\text { RRID: } \\
\text { AB_945772 }\end{array}$ \\
\hline
\end{tabular}


continued

\begin{tabular}{|c|c|c|}
\hline Reagent or resource & Source & Identifier \\
\hline $\begin{array}{l}\text { Anti- HNF4a (Rabbit } \\
\text { monoclonal) }\end{array}$ & $\begin{array}{l}\text { Cell Signaling } \\
\text { Technology }\end{array}$ & $\begin{array}{l}\text { \#3113S; RRII } \\
\text { AB_2295208 }\end{array}$ \\
\hline Anti-MCL1 (Rabbit polyclonal) & $\begin{array}{l}\text { Cell Signaling } \\
\text { Technology }\end{array}$ & $\begin{array}{l}\# 4572 ; \mathrm{RRID} \\
\text { AB_2281980 }\end{array}$ \\
\hline $\begin{array}{l}\text { Anti-PAX6 [AD1.5] (Mouse } \\
\text { monoclonal) }\end{array}$ & Millipore & $\begin{array}{l}\text { Ab570718; } \\
\text { RRID: } \\
\text { AB_570718 }\end{array}$ \\
\hline Anti-PDX1 (Goat polyclonal) & R\&D Systems & $\begin{array}{l}\text { Af2419 RRID } \\
\text { AB_355257 }\end{array}$ \\
\hline $\begin{array}{l}\text { Anti-PUMA (Rabbit } \\
\text { polyclonal) }\end{array}$ & $\begin{array}{l}\text { Cell Signaling } \\
\text { Technology }\end{array}$ & $\begin{array}{l}\# 4976 ; \text { RRID } \\
\text { AB_206455 }\end{array}$ \\
\hline Anti-SFRP5 (Rabbit polyclonal) & Abcam & $\begin{array}{l}\text { Ab230425; } \\
\text { RRID: NA }\end{array}$ \\
\hline $\begin{array}{l}\text { Donkey Anti-Mouse lgG }(\mathrm{H}+ \\
\text { L) Highly Cross-Adsorbed } \\
\text { secondary antibody, Alexa } \\
\text { Fluor Plus } 647\end{array}$ & Invitrogen & $\begin{array}{l}\text { Ab32787 } \\
\text { RRID: } \\
\text { AB_276283C }\end{array}$ \\
\hline Goat Anti-Mouse lgG HRP & Santa Cruz & $\begin{array}{l}\text { SC-2005; RRI } \\
\text { AB_631736 }\end{array}$ \\
\hline $\begin{array}{l}\text { Donkey Anti-Rabbit lgG }(\mathrm{H}+ \\
\text { L) Alexa Fluor } 488\end{array}$ & Invitrogen & $\begin{array}{l}\text { A21206; RRI } \\
\text { AB_2535792 }\end{array}$ \\
\hline Goat Anti-Rabbit lgG HRP & Santa Cruz & $\begin{array}{l}\text { SC-2004; RRI } \\
\text { AB_631746 }\end{array}$ \\
\hline $\begin{array}{l}\text { Donkey Anti-Goat lgG }(\mathrm{H}+\mathrm{L}) \\
\text { Cross-Adsorbed, Alex } \\
\text { Fluor } 488\end{array}$ & Thermo Fisher Scientific & $\begin{array}{l}\text { A11055; RRI } \\
\text { AB_2534102 }\end{array}$ \\
\hline $\begin{array}{l}\text { Donkey Anti-Mouse }(\mathrm{H}+\mathrm{L}) \\
\text { Highly Cross-Adsorbed, Alex } \\
\text { Fluor } 488\end{array}$ & Thermo Fisher Scientific & $\begin{array}{l}\text { A21202; RRI } \\
\text { AB_141607 }\end{array}$ \\
\hline Bacterial and Virus Strains & & \\
\hline N/A & N/A & N/A \\
\hline Deposited Data & & \\
\hline RNA-Seq & GEO & GSE13606 \\
\hline Experimental Models: Cell Line & & \\
\hline $\begin{array}{l}\text { Mouse: CF-1 mouse } \\
\text { embryonic fibroblasts }\end{array}$ & MTI-GlobalStem & GSC-6001C \\
\hline HEK293FT & Thermo Fisher Scientific & R70007 \\
\hline Human ESC W09 (Female) & $\begin{array}{l}\text { WiCell Research } \\
\text { Institute, Inc }\end{array}$ & 15-W0038 \\
\hline Human iPSCs iAGb (Male) & $\begin{array}{l}\text { Reprogrammed from } \\
\text { fibroblast AG16102, } \\
\text { Coriell Institute }\end{array}$ & N/A \\
\hline
\end{tabular}

Oligonucleotides continued

\begin{tabular}{|c|c|c|}
\hline Reagent or resource & Source & Identifier \\
\hline $\begin{array}{l}\text { QPCR primers, shRNA oligos, } \\
\text { see Table S2 }\end{array}$ & This paper & N/A \\
\hline \multicolumn{3}{|c|}{ Chemical, peptides and recombinant proteins } \\
\hline Activin A & R\&D system & $338-A C-50$ \\
\hline ALK5ill & ENZO & $\begin{array}{l}\text { ALX-270-445- } \\
\text { M001 }\end{array}$ \\
\hline Ascorbic acid & Sigma & A8960 \\
\hline Betacellulin & Cell Signaling & 5235SF \\
\hline B-27 Serum Minus Vitamin A & Thermo Fisher Scientific & \#12587010 \\
\hline$\beta$-mercaptoethanol & Thermo Fisher Scientific & $21985-023$ \\
\hline Calcium chloride & Sigma & C-5670 \\
\hline CHIR9021 & Tocris & 4423 \\
\hline CMRL 1066 Supplemented & Mediatech Inc & $99-603-C V$ \\
\hline CMRL Medium 1066 & Life Technologies & 11530-037 \\
\hline Collagenase IV & Life Technologies & 17104019 \\
\hline DAKO mounting medium & DAKO & S3023 \\
\hline DAPI & Sigma & D9542 \\
\hline DAPT & Abcam & Ab120633 \\
\hline Dispase in DMEM/F12 & STEMCELL Technologies & 07923 \\
\hline $\mathrm{D}(+)$-Glucose & WAKO & 049-31165 \\
\hline Donkey serum & Merck & S-30 \\
\hline DMEM F12 media & Invitrogen & 10565042 \\
\hline DMEM/High Glucose Media & Hyclone & SH30243.01 \\
\hline DMSO & Sigma & D2650 \\
\hline FAF-BSA & Proliant & 68700 \\
\hline FGF2 & Miltenyi Biotec & 130-093-838 \\
\hline FGF7 & Mitenyi Biotec & 130037178 \\
\hline Gelatin (Porcine) & Sigma & G1890 \\
\hline Glutamax $^{\top \mathrm{M} M}$ Supplement & Invitrogen & 35050038 \\
\hline HEPES Buffer $1 \mathrm{M}$ & STEMCELL Technologies & 07200 \\
\hline $\begin{array}{l}\text { HyClone Phosphate Buffered } \\
\text { Saline solution }\end{array}$ & $\begin{array}{l}\text { GE Healthcare Life } \\
\text { Sciences }\end{array}$ & SH30256.01 \\
\hline $\begin{array}{l}\text { Hyclone }{ }^{\mathrm{TM}} \text { Fetal bovine } \\
\text { serum (South America) }\end{array}$ & Hyclone & SV30160.03 \\
\hline ITS-X & Life Technologies & 51500056 \\
\hline $\begin{array}{l}\text { KnockOut }^{\mathrm{TM}} \text { serum } \\
\text { replacement }\end{array}$ & Gibco & 10828028 \\
\hline LDN193189 & Sigma & SML0559 \\
\hline L-Glutamine & Sigma & G8540 \\
\hline & Invitrogen & 11668027 \\
\hline
\end{tabular}


continued

\begin{tabular}{|c|c|c|}
\hline Reagent or resource & Source & Identifier \\
\hline \multicolumn{3}{|l|}{ Lipofectamine $^{\text {TM }} 2000$} \\
\hline \multicolumn{3}{|l|}{ Transfection Reagent } \\
\hline LY294002 & LC labs & L-7962 \\
\hline MCDB131 & Life Technologies & 10372019 \\
\hline $\begin{array}{l}\text { MEM Non-Essential Amino } \\
\text { Acids }(100 \times)\end{array}$ & Life Technologies & $11140-050$ \\
\hline $\begin{array}{l}\text { M-PER }{ }^{\mathrm{TM}} \text { Mammalian Protein } \\
\text { Extraction Reagent }\end{array}$ & Thermo Scientific & 78501 \\
\hline mTESR $^{\mathrm{TM}} 1$ Basal Medium & STEMCELL Technologies & 85851 \\
\hline $\mathrm{NaHCO}_{3}$ & Sigma & S5761-500G \\
\hline QVD-OPh & Cayman Chemical & 15260 \\
\hline PDBu & Tocris & 4153 \\
\hline Penicillin-Streptomycin & Thermo Fisher Scientific & 15140122 \\
\hline Polybrene & Millipore & TR-1003-G \\
\hline Retinoic Acid & WAKO & 186-01114 \\
\hline RPMI-1640 & Gibco & 11875093 \\
\hline SANT1 & Santa Cruz & Sc-203253 \\
\hline TeSR $^{T M}{ }_{-E 8^{T M}}$ Basal Medium & STEMCELL Technologies & 05990 \\
\hline TeSR ${ }^{T M}{ }_{-E 8}{ }^{T M} 25 X$ Supplement & STEMCELL Technologies & 05992 \\
\hline TrypLE Express & Life Technologies & 12604021 \\
\hline Trypsin-EDTA (0.25\%) & Life Technologies & 25200056 \\
\hline T3 & Millipore & 642511 \\
\hline Vitamin B3 (Nicotinamide) & Sigma & N0636-100G \\
\hline Vitamin C (L-Ascorbic acid) & WAKO & 012-04802 \\
\hline WEHI-539 & ApexBio & A3935 \\
\hline $\begin{array}{l}\text { XXI (Gamma-Secretase } \\
\text { Inhibitor) }\end{array}$ & Millipore & 565790 \\
\hline Y-27632 & STEMCELL Technologies & 72302 \\
\hline \multicolumn{3}{|l|}{ Critical commercial assays } \\
\hline $\begin{array}{l}\text { High Capacity cDNA Reverse } \\
\text { Transcription Kit }\end{array}$ & Applied Biosystems & 4368813 \\
\hline $\begin{array}{l}\text { iTaq }{ }^{\text {TM }} \text { Universal SYBR }{ }^{\oplus} \text { Green } \\
\text { Supermix }\end{array}$ & Bio-Rad & 1725124 \\
\hline Lenti- $X^{T M}$ p24 Rapid Titer Kit & Clontech & 632200 \\
\hline $\begin{array}{l}\text { LIVE/DEAD Viability/ } \\
\text { Cytotoxicity Kit }\end{array}$ & Thermo Fisher Scientific & L-3224 \\
\hline NucleoBond ${ }^{\oplus}$ Xtra Midi & Macherey-Nagel & 740410.50 \\
\hline Nucleospin ${ }^{\circledR}$ Plasmid EasyPure & Macherey-Nagel & 740727.250 \\
\hline Phusion High-Fidelity DNA & Thermo Fisher Scientific & F530S \\
\hline Polymerase & & \\
\hline & Thermo Fisher Scientific & 23227 \\
\hline
\end{tabular}

continued

\begin{tabular}{|c|c|c|}
\hline Reagent or resource & Source & Identifier \\
\hline \multicolumn{3}{|l|}{ Pierce $^{T M}$ BCA Protein } \\
\hline \multicolumn{3}{|l|}{ Assay Kit } \\
\hline PureLink $^{\mathrm{TM}}$ Quick PCR & Invitrogen & K310002 \\
\hline \multicolumn{3}{|l|}{ Purification Kit } \\
\hline \multicolumn{3}{|l|}{ Nucleospin" RNA } \\
\hline Seahorse XF Base Medium & Agilent & $\begin{array}{l}102353-100- \\
100\end{array}$ \\
\hline $\begin{array}{l}\text { Seahorse XF Glycolysis Stress } \\
\text { Test Kit }\end{array}$ & Test Kit & $103020-100$ \\
\hline Seahorse XF Mito Stress Kit & Agilent & $103015-100$ \\
\hline $\begin{array}{l}\text { SuperSignal }{ }^{\mathrm{TM}} \text { West Dura } \\
\text { Extended Duration Substrate }\end{array}$ & Extended Duration Substrate & 34076 \\
\hline \multicolumn{3}{|l|}{ Softwares and Algorithms } \\
\hline AxioVision LE & Zeiss & Version 4.8.2 \\
\hline FlowJo 10 & Flowjo & Version 10 \\
\hline Seahorse XFe96 Analyzer & Agilent & S7800B \\
\hline \multicolumn{2}{|l|}{ Software } & Version 2.6.1 \\
\hline \multicolumn{3}{|l|}{ Others } \\
\hline CFX384 ${ }^{\mathrm{TM}}$ Real-Time System & Bio-Rad & 1855485 \\
\hline Coverslips $18 \times 18 \mathrm{~mm}$ & Marienfeld & 0101030 \\
\hline $\begin{array}{l}\text { NanoDrop } \\
1000 \text { spectrophotometer }\end{array}$ & Thermo Fisher Scientific & $\vee 3.8$ \\
\hline Nikon Eclipse Inverted & Nikon & TS-100 \\
\hline $\begin{array}{l}\text { Olympus Fluoview } 1000 \\
\text { Inverted Confocal }\end{array}$ & Olympus & FV1000 \\
\hline $\begin{array}{l}\text { Optima L-100 XP } \\
\text { Ultracentrifuge }\end{array}$ & Beckman Coulter & $L-100 X P$ \\
\hline $\begin{array}{l}\text { SuperFrost Plus }{ }^{\mathrm{Tm}} \\
\text { Adhesion slides }\end{array}$ & Thermo Fisher Scientific & 10149870 \\
\hline $\begin{array}{l}\text { SW28 Ti Swinging-Bucket } \\
\text { Aluminum Rotor }\end{array}$ & Beckman Coulter & 342207 \\
\hline Ultra-Clear tubes & Beckman Coulter & 344058 \\
\hline
\end{tabular}

\section{Acknowledgements}

We thank members of the Teo laboratory for the critical reading of this paper and Ronnie Yee for performing cell counting. L.S.W.L. and L.N. are supported by the $A^{*}$ STAR Graduate Academy ( $\left.A^{*} G A\right)$. A.K.K.T. is supported by the Institute of Molecular and Cell Biology (IMCB), A*STAR, NMRC Open Fund-Young Individual Research Grant (OF-YIRG) OFYIRG16may014, A*STAR ETPL Gap Funding ETPL/18-GAP005-R2OH, Lee Foundation Grant SHTX/LFG/002/2018, Skin Innovation Grant SIG18011, NMRC OF-LCG/DYNAMO, FY2019 SingHealth Duke-NUS Surgery Academic Clinical Program Research Support Program Grant, the Precision Medicine and Personalized Therapeutics Joint Research Grant 2019, the Industry Alignment Fund - Industry Collaboration Project (IAFICP) and the $2^{\text {nd }} A^{*}$ STAR-AMED Joint Grant Call $192 B 9002$. 


\section{Author details}

${ }^{1}$ Stem Cells and Diabetes Laboratory, Institute of Molecular and Cell Biology, A*STAR, Proteos, Singapore 138673, Singapore. ${ }^{2}$ School of Biological Sciences, Nanyang Technological University, Singapore 637551, Singapore.

${ }^{3}$ Computational and Statistical Systems Biology, Institute of Molecular and Cell Biology, A*STAR, Proteos, Singapore 138673, Singapore. ${ }^{4}$ Department of Biochemistry, Yong Loo Lin School of Medicine, National University of Singapore, Singapore 117596, Singapore. ${ }^{5}$ Molecular Engineering Lab, Proteos, Singapore 138673, Singapore. ${ }^{6}$ Department of Medicine, Yong Loo Lin School of Medicine, National University of Singapore, Singapore 119228, Singapore

\section{Data availability}

Accession number for RNA-Seq data in GEO is GSE136064.

\section{Conflict of interest}

The authors declare that they have no conflict of interest.

\section{Publisher's note}

Springer Nature remains neutral with regard to jurisdictional claims in published maps and institutional affiliations.

Supplementary Information accompanies this paper at (https://doi.org/ 10.1038/s41419-020-2589-7).

Received: 4 December 2019 Revised: 4 May 2020 Accepted: 5 May 2020 Published online: 18 May 2020

\section{References}

1. Teo, A. K., Wagers, A. J. \& Kulkarni, R. N. New opportunities: harnessing induced pluripotency for discovery in diabetes and metabolism. Cell Metab. 18, 775-791 (2013)

2. Loo, L. S. W., Lau, H. H., Jasmen, J. B., Lim, C. S. \& Teo, A. K. K. An arduous journey from human pluripotent stem cells to functional pancreatic beta cells. Diabetes Obes. Metab. 20, 3-13 (2018).

3. TeSlaa, T., Setoguchi, K. \& Teitell, M. A. Mitochondria in human pluripotent stem cell apoptosis. Semin Cell Dev. Biol. 52, 76-83 (2016).

4. Wang, E. S. et al. Fas-activated mitochondrial apoptosis culls stalled embryonic stem cells to promote differentiation. Curr. Biol. 25, 3110-3118 (2015).

5. Fuchs, Y. \& Steller, H. Programmed cell death in animal development and disease. Cell 147, 742-758 (2011).

6. Adams, J. M. \& Cory, S. The Bcl-2 protein family: arbiters of cell survival. Science 281, 1322-1326 (1998).

7. Wei, M. C. et al. Proapoptotic BAX and BAK: a requisite gateway to mitochondrial dysfunction and death. Science 292, 727-730 (2001).

8. Opferman, J. T. \& Kothari, A. Anti-apoptotic BCL-2 family members in development. Cell Death Differ. 25, 37-45 (2018).

9. Ardehali, R. et al. Overexpression of BCL2 enhances survival of human embryonic stem cells during stress and obviates the requirement for serum factors. Proc. Natl Acad. Sci. USA 108, 3282-3287 (2011).

10. Dumitru, R. et al. Human embryonic stem cells have constitutively active Bax at the Golgi and are primed to undergo rapid apoptosis. Mol. Cell 46, 573-583 (2012).
11. Teo, A. K. et al. Early developmental perturbations in a human stem cell model of MODY5/HNF1B pancreatic hypoplasia. Stem Cell Rep. 6, 357-367 (2016).

12. Teo, A. K. et al. PDX1 binds and represses hepatic genes to ensure robust pancreatic commitment in differentiating human embryonic stem cells. Stem Cell Rep. 4, 578-590 (2015).

13. Lessene, G. et al. Structure-guided design of a selective $B C L-X(L)$ inhibitor. Nat. Chem. Biol. 9, 390-397 (2013).

14. Heller, R. S. et al. Expression patterns of Wnts, Frizzleds, SFRPs, and misexpression in transgenic mice suggesting a role for Wnts in pancreas and foregut pattern formation. Dev. Dyn. 225, 260-270 (2002).

15. Papadopoulou, S. \& Edlund, H. Attenuated Wnt signaling perturbs pancreatic growth but not pancreatic function. Diabetes 54, 2844-2851 (2005).

16. Li, Y. et al. Sfrp5 coordinates foregut specification and morphogenesis by antagonizing both canonical and noncanonical Wnt11 signaling. Genes Dev. 22, 3050-3063 (2008).

17. Stuckenholz, C. et al. Sfrp5 modulates both Wnt and BMP signaling and regulates gastrointestinal organogenesis [corrected] in the zebrafish, Danio rerio. PLoS ONE 8, e62470 (2013).

18. Pagliuca, F. W. et al. Generation of functional human pancreatic beta cells in vitro. Cell 159, 428-439 (2014).

19. Matsuzaki, Y. et al. Role of bcl-2 in the development of lymphoid cells from the hematopoietic stem cell. Blood 89, 853-862 (1997).

20. Kamada, S. et al. bcl-2 deficiency in mice leads to pleiotropic abnormalities: accelerated lymphoid cell death in thymus and spleen, polycystic kidney, hair hypopigmentation, and distorted small intestine. Cancer Res. 55, 354-359 (1995).

21. Michaelidis, T. M. et al. Inactivation of bcl-2 results in progressive degeneration of motoneurons, sympathetic and sensory neurons during early postnatal development. Neuron 17, 75-89 (1996).

22. Savitt, J. M., Jang, S. S., Mu, W., Dawson, V. L. \& Dawson, T. M. Bcl-x is required for proper development of the mouse substantia nigra. J. Neurosci. 25 6721-6728 (2005).

23. Carrington, E. M. et al. Islet beta-cells deficient in BCl-XL develop but are abnormally sensitive to apoptotic stimuli. Diabetes 58, 2316-2323 (2009).

24. Alavian, K. N. et al. BCl-xL regulates metabolic efficiency of neurons through interaction with the mitochondrial F1FO ATP synthase. Nat. Cell Biol. 13 1224-1233 (2011)

25. Sung, K. F. et al. Prosurvival BCl-2 proteins stabilize pancreatic mitochondria and protect against necrosis in experimental pancreatitis. Exp. Cell Res. 315 1975-1989 (2009).

26. Lindenboim, L., Kringel, S., Braun, T., Borner, C. \& Stein, R. Bak but not Bax is essential for BCl-xS-induced apoptosis. Cell Death Differ. 12, 713-723 (2005).

27. Brooks, C. et al. Bak regulates mitochondrial morphology and pathology during apoptosis by interacting with mitofusins. Proc. Natl Acad. Sci. USA 104 11649-11654 (2007).

28. Willis, S. N. et al. Proapoptotic Bak is sequestered by $\mathrm{Mcl}-1$ and $\mathrm{BCl}-\mathrm{xL}$, but not BCl-2, until displaced by BH3-only proteins. Genes Dev. 19, 1294-1305 (2005).

29. Sattler, M. et al. Structure of $\mathrm{BCl}-\mathrm{xL}$-Bak peptide complex: recognition between regulators of apoptosis. Science $\mathbf{2 7 5}$, 983-986 (1997)

30. Ito, K. \& Suda, T. Metabolic requirements for the maintenance of self-renewing stem cells. Nat. Rev. Mol. Cell Biol. 15, 243-256 (2014).

31. Chen, Y. B. et al. BCl-XL regulates mitochondrial energetics by stabilizing the inner membrane potential. J. Cell Biol. 195, 263-276 (2011). 